\title{
Dust-air pollution dynamics over the eastern Mediterranean
}

\author{
M. Abdelkader ${ }^{1}$, S. Metzger ${ }^{1,2}$, R. E. Mamouri ${ }^{3}$, M. Astitha ${ }^{4}$, L. Barrie ${ }^{5}$, Z. Levin ${ }^{1,6}$, and J. Lelieveld ${ }^{1,2}$ \\ ${ }^{1}$ Energy, Environment and Water Research Center, The Cyprus Institute, Nicosia, 2121, Cyprus \\ ${ }^{2}$ Air Chemistry Department, Max Planck Institute for Chemistry, Mainz, 55128, Germany \\ ${ }^{3}$ Department of Civil Engineering and Geomatics, Cyprus University of Technology, Limassol, 3036, Cyprus \\ ${ }^{4}$ Department of Civil Engineering, University of Connecticut, Storrs-Mansfield, 06269, USA \\ ${ }^{5}$ Department of Geological Sciences, Stockholm University, Stockholm, 106 91, Sweden \\ ${ }^{6}$ Tel Aviv University, Tel Aviv, 39040, Israel
}

Correspondence to: M. Abdelkader (m.abdelkader@cyi.ac.cy) and S. Metzger (s.metzger@cyi.ac.cy)

Received: 12 February 2015 - Published in Atmos. Chem. Phys. Discuss.: 11 March 2015

Revised: 22 July 2015 - Accepted: 6 August 2015 - Published: 19 August 2015

\begin{abstract}
Interactions of desert dust and air pollution over the eastern Mediterranean (EM) have been studied, focusing on two distinct dust transport events on 22 and 28 September 2011. The atmospheric chemistry-climate model EMAC has been used at about $50 \mathrm{~km}$ grid spacing, applying an online dust emission scheme and calcium as a proxy for dust reactivity. EMAC includes a detailed tropospheric chemistry mechanism, aerosol microphysics and thermodynamics schemes to describe dust "aging". The model is evaluated using ground-based observations for aerosol concentrations and aerosol optical depth (AOD) as well as satellite observations. Simulation results and back trajectory analysis show that the development of synoptic disturbances over the EM can enhance dust transport from the Sahara and Arabian deserts in frontal systems that also carry air pollution to the EM. The frontal systems are associated with precipitation that controls the dust removal. Our results show the importance of chemical aging of dust, which increases particle size, dust deposition and scavenging efficiency during transport, overall reducing the lifetime relative to non-aged dust particles. The relatively long travel periods of Saharan dust result in more sustained aging compared to Arabian dust. Sensitivity simulations indicate 3 times more dust deposition of aged relative to pristine dust, which significantly decreases the dust lifetime and loading.
\end{abstract}

\section{Introduction}

\subsection{Importance of atmospheric dust}

The atmospheric dust cycle, a fundamental component of the Earth system, can strongly influence air quality and climate. Atmospheric dust causes a radiative forcing of climate by direct and indirect effects. Dust particles scatter solar shortwave radiation back into space, which can enhance the Earth's albedo. Indirect effects result from dust particles acting as cloud condensation nuclei $(\mathrm{CCN})$, which can affect the droplet number concentration and reflectivity of clouds, and either enhance (Yin et al., 2002) or suppress (Rosenfeld et al., 2001) precipitation formation depending on their mineralogy and solubility. Furthermore, pristine dust particles are the best natural ice nuclei (IN), especially over the eastern Mediterranean (EM) region (Ardon-Dryer and Levin, 2014). Moreover, dust particles provide a surface for heterogeneous chemical reactions, which affects dust-climate interactions (Dentener et al., 1996; Bauer et al., 2004; Mogili et al., 2006; Bauer et al., 2007; Astitha et al., 2010; Crowley et al., 2010, among others). Dust influences a wide range of atmospheric physical, chemical and biogeochemical processes, including the marine and terrestrial biosphere through the transport of nutrients like iron (Mahowald et al., 2009) and phosphorus (Nenes et al., 2011).

The impact of atmospheric dust on the Earth's climate is controlled by the balance between the emissions and the removal of the dust from the atmosphere, which is altered by chemical and physical processes that occur during transport. 
This "aging" process poses a challenge in quantifying the direct and indirect radiative forcing of mineral dust. It is one of the central uncertainties in modeling the dust cycle in climate, atmospheric chemistry and Earth system models (Stocker et al., 2014), especially when considering dust removal by wet deposition (Schulz et al., 2012). Therefore, an accurate modeling of mineral dust emissions, transport, and chemistry is required to enhance our quantitative understanding of the global dust abundance, dust storm episodes and their impacts on climate, air quality and biogeochemical cycles.

\subsection{Dust transport}

The transport of Saharan dust in addition to that from Arabian deserts are the main sources of atmospheric dust in the EM region (Pey et al., 2013), a regular atmospheric phenomenon in this region (Ganor et al., 2010). Typically, the majority of dust outbreaks are related to steep surface pressure gradients between northern Africa and the Mediterranean (Dayan et al., 2008). Saharan dust is generally mobilized in Libya, Egypt and the Bodele Depression (Pey et al., 2013) during the local dry season from October to April (Goudie and Middleton, 2006) and then transported over the EM by Sharav cyclones (Ganor and Mamane, 1982; Moulin et al., 1998; Goudie and Middleton, 2006; Ganor et al., 2010) or Khamsin events (Ganor and Mamane, 1982). These cyclones are generated along the polar front and subtropical jet streams (Kallos et al., 2006) as a result of differential heating between relatively colder oceanic waters to the north and warmer land masses to the south (Goudie and Middleton, 2006). These synoptic conditions are usually associated with a cold front and are often accompanied by rain over the EM (Alpert and Ganor, 1993). In addition, the EM is affected by dust transport from the Negev desert, controlled by a range of synoptic systems, e.g., Cyprus lows, Red Sea troughs, Persian troughs, anticyclones over the Levant and to the east of the region. The majority, i.e., about two-thirds of the yearly dust events are caused by Cyprus lows (Dayan et al., 2008). Since Cyprus lows are often associated with precipitation, the residence time of dust particles in the atmosphere can be relatively short. In case of a barometric trough penetrating from the Red Sea into the EM, it can be as short as 1 day (Dayan et al., 1991). Dayan et al. (2008) studied events where dust is transported from the Sahara, indicating that the average residence time is about 4 days before the dust is removed by rain. The combination of dust transport from the Sahara and Arabian deserts results in numerous and very intense dust episodes over the EM and Cyprus (Pey et al., 2013). In general, the transport of Saharan dust usually extends into relatively deep atmospheric layers and is characterized by a regional extension over the Mediterranean Basin. Typically, dust is transported over the EM at an elevation of $1.5-6.5 \mathrm{~km}$ above sea level and commonly at about $2.5 \mathrm{~km}$ (Levin et al., 2005; Papayannis et al., 2005;
Ganor et al., 2010; Mamouri et al., 2013). Since Saharan dust events last longer and have higher mass loadings compared to the Negev and Arabian desert dust events, they may have stronger impacts on the EM region (Dayan et al., 1991), however, there are large uncertainties. In particular, the interaction of atmospheric dust particles with air pollution from eastern and western Europe and long-range transport from North America and Asia (Lelieveld et al., 2002; Levin et al., 2005, among others) remains to be scrutinized, leading to the focus of this study.

\subsection{Dust-air pollution interactions}

During transport dust undergoes chemical aging as a result of the condensation of low or semi-volatile compounds on the particle surface. The chemical aging of the dust particles can affect water uptake, which in turn controls the gas-liquidsolid partitioning of various gaseous compounds, including sulfuric, nitric and hydrochloric acid. Previous studies (Levin et al., 1996) have focused on the dust coating by sulfate and the resulting effect on rain formation in the EM. More recent modeling studies have addressed the relative importance of mineral cations and organics on the gas-aerosol partitioning of reactive nitrogen compounds, since cations such as calcium largely determine the neutralization level of sulfate, nitrate, chloride and organic compounds (Trebs et al., 2005; Metzger et al., 2006). In addition, various other heterogeneous reactions occur on the dry surface of dust particles that may depend on their mineralogy and alkalinity. Soluble compounds eventually alter the dust chemical composition, shape and size distribution and the atmospheric lifetime. Chemical aging of dust particles may further control the activation of CCN, reduce the IN efficiency (Reitz et al., 2011), or affect the scavenging efficiency (Manktelow et al., 2010). Typically, the atmospheric lifetime of dust particles depends on (1) dry removal, which mainly depends on the ambient (wet) particle size and (2) on wet deposition. The latter includes in- and below-cloud scavenging, and depends on the chemical composition of the dust surface, which can include a large fraction of water in case dust particles are coated by hydrochloric or nitric acids and/or are exposed to high relative humidity. The fraction of coated dust surface, however, critically depends on the aging mechanism. Changes in composition, size and shape of the dust particles due to the various aging processes affect the associated radiative forcing. Scattering and adsorption of sunlight is important for the influence of dust on the Earth's climate. However, to what extent chemical aging of mineral dust is important for the climate feedback mechanisms is largely unknown (Koop and Mahowald, 2013).

\subsection{Dust-air pollution modeling - this study}

This work presents a modeling case study based on the atmospheric chemistry-climate model EMAC. The model setup 
includes a detailed treatment of dust aging, which is based on the condensation of different soluble compounds and the associated water uptake of various atmospheric particles and a chemical speciation of mineral dust and sea salt compounds, which are calculated online. Dry and wet dust removal are based on the ambient particle radius and $\mathrm{pH}$-dependent scavenging processes. The EMAC setup is described in Sect. 2 and evaluated in Sect. 3.1 based on various long-term observations. In Sect. 3.2 we focus on the dynamics of two distinct events where dust-air pollution interactions over the EM play a role. Section 3.3 analyzes the dust outflow dynamics of the case studies, while the effects of dust aging are investigated in Sect. 3.4 and 3.5. We conclude with Sect. 4.

\section{Model description}

The ECHAM5/MESSy2 atmospheric chemistry (EMAC) model is used to study dust-air pollution dynamics over the EM. EMAC is a numerical chemistry and climate simulation system that is based on sub-models that describe tropospheric and middle-atmosphere processes and their interactions with oceans, land and human influences (Jöckel et al., 2010). This Modular Earth Submodel System (MESSy) links multi-institutional computer codes. The core atmospheric model is the Fifth generation European Centre Hamburg Atmospheric general circulation Model (ECHAM5, Roeckner et al., 2006). For the present study we applied EMAC (ECHAM5 version 5.3.02, MESSy version 2.41) with the submodels AEROPT, CLOUD, CONVECT, CVTRANS, DDEP, GMXe, JVAL, LNOX, MECCA, OFFEMIS, ONEMIS, RAD4ALL, SCAV, SEDI, TNUDGE, TROPOP (http: //www.messy-interface.org/). For the global anthropogenic emissions we follow Pozzer et al. (2012) and de Meij et al. (2012) and use the EDGARv4 inventory, which has been prepared in the framework of the CIRCE project with a focus on the Mediterranean region (http://www.iddri.org/Projets/ CIRCE-Project-Research). The emission inventory includes greenhouse gases, $\mathrm{NO}_{x}, \mathrm{CO}$, non-methane volatile organic compounds (NMVOCs), $\mathrm{NH}_{3}, \mathrm{SO}_{2}$, black carbon (BC) and organic carbon (OC) from fossil fuel and biofuel use. The emissions are geographically distributed according to the EDGAR4 2009 database which has a monthly resolution. The monthly large-scale biomass burning emissions of OC, $\mathrm{BC}$ and $\mathrm{SO}_{2}$, are based on GFED version 3 (Global Fire Emissions Database) (van der Werf et al., 2010).

The aerosol setup has been described in detail by Pringle et al. (2010); Tost et al. (2010); de Meij et al. (2012); Pozzer et al. (2012). The setup is based on the aerosol microphysics sub-model GMXe, described in Pringle et al. (2010), which is coupled to the gas-aerosol partitioning scheme ISORROPIA-II (Fountoukis and Nenes, 2007). Our model version distinguishes aerosol particles in seven modes: four Soluble (nucleation, Aitken, accumulation, coarse) and three INSoluble modes (Aitken, accumulation, coarse), with the initial radii of $0.0015,0.025,0.25$ and $2.5 \mu \mathrm{m}$ for the nucleation, Aitken, accumulation and coarse mode and the corresponding sigma values of $1.59,1.59,1.59$ and 2.00 , respectively. We consider the complexity of the aerosol thermodynamics as investigated in Metzger et al. (2006), by considering case F4 since ISORROPIA-II used here does not include organic salt compounds in the gas-aerosol partitioning and aerosol neutralization framework. Within EMAC, the dust particles are emitted online following Astitha et al. (2012) (e.g., governed by model dynamics, precipitation and soil moisture) in either the INSoluble accumulation and/or coarse mode and only upon aging and transport they can be transferred to the respective Soluble accumulation and/or coarse modes. The aging depends on the available condensable compounds calculated within the chemistry scheme (Sander et al., 2005). In addition, via coagulation and hygroscopic growth the size-distribution can change and small particles are transferred to larger sizes, i.e., for dust from accumulation to coarse mode, whereby hygroscopic growth of bulk dust and dust salt compounds is only allowed in the soluble modes.

For proper representation of chemical aging, we use a comprehensive chemistry scheme that allows for the production of different aerosol precursor gases, i.e., the major inorganic acids $\left(\mathrm{H}_{2} \mathrm{SO}_{4}, \mathrm{HNO}_{3}, \mathrm{HCl}\right)$, which are all subsequently considered for the chemical aging of dust and other primary aerosol particles (i.e., $\mathrm{BC}$ and $\mathrm{OC}$ ). The condensation of the acids yields anions, i.e., sulfate $\left(\mathrm{SO}_{4}^{2-}\right)$, bi-sulfate $\left(\mathrm{HSO}_{4}^{-}\right)$, nitrate $\left(\mathrm{NO}_{3}^{-}\right)$, and chloride $\left(\mathrm{Cl}^{-}\right)$, respectively, while the additional condensation of ammonia $\left(\mathrm{NH}_{3}\right)$ yields a semi-volatile cation, ammonium $\left(\mathrm{NH}_{4}^{+}\right)$, and can neutralize the anions leading to hygroscopic salt compounds that coat (age) the dust particles. This transformation changes the solubility of the originally insoluble pristine particles, which in turn alters the aerosol size distribution. The latter is a key parameter and important for aerosol-radiation feedback and aerosol in-cloud processing (nucleation scavenging) and below-cloud processing (impaction scavenging). The scavenging processes applied in our study are based on Tost et al. (2006) and include a detailed scavenging chemistry that fully couples the aerosol and gas-phase chemistry with liquid cloud water and ice crystals.

To additionally account for the major mineral cations, we have extended our EMAC version to include a simple chemical speciation of the natural aerosol emission fluxes. We consider the calcium cation $\left(\mathrm{Ca}^{2+}\right)$ as a chemically reactive tracer on the dust, emitted in the insoluble accumulation and insoluble coarse modes as a fraction of the dust emission flux, i.e., 25 and $5 \%$ for the accumulation and coarse mode, respectively. These fractions have been derived from a comprehensive sensitivity study to achieve a good agreement of both (1) lumped aerosol concentrations of $\mathrm{Ca}^{2+}$, magnesium $\left(\mathrm{Mg}^{2+}\right)$, potassium $\left(\mathrm{K}^{+}\right)$, ammonium $\left(\mathrm{NH}_{4}^{+}\right)$, sodium $\left(\mathrm{Na}^{+}\right), \mathrm{SO}_{4}^{2-}, \mathrm{HSO}_{4}^{-}, \mathrm{NO}_{3}^{-}$and $\mathrm{Cl}^{-}$with various EMEP and 
CASTNET station observations, and (2) PM and AOD model results with independent observations of EMEP, AERONET and different satellite products (MODIS, MISR, SeaWIFS, ENVISAT, CALIPSO). Table 1 (in the Supplement) shows the long-term average of the model results and the station observations for major aerosol properties, which are part of a comprehensive model evaluation that will be presented separately. We apply chemical speciation for the bulk sea salt emission flux, i.e., we consider the cations $\mathrm{Na}^{+}, \mathrm{K}^{+}, \mathrm{Mg}^{2+}$, $\mathrm{Ca}^{2+}$ and the anions $\mathrm{Cl}^{-}$and $\mathrm{SO}_{4}^{2-}$ as tracers for the online calculated sea salt emissions. Additionally, $\mathrm{K}^{+}$is used for biomass burning emissions being emitted here only in the insoluble Aitken mode. This chemical speciation has been determined such that the model concentrations best match the available EMEP and CASTNET measurement data for the period 2000-2013 (to be published separately). For the importance of mineral cations in gas-aerosol partitioning modeling studies with a focus on the EM we refer to Metzger et al. (2006).

The dust particles can be present in our setup in four modes, each represented by various calcium compounds that chemically characterize the bulk dust emissions depending on the level of aging. We account for the water uptake of various major mineral salt compounds, i.e., $\mathrm{CaSO}_{4}, \mathrm{Ca}\left(\mathrm{NO}_{3}\right)_{2}$, $\mathrm{CaCl}_{2}, \mathrm{MgSO}_{4}, \mathrm{Mg}\left(\mathrm{NO}_{3}\right)_{2}, \mathrm{MgCl}_{2}, \mathrm{Na}_{2} \mathrm{SO}_{4}, \mathrm{NaNO}_{3}, \mathrm{NaCl}$, $\mathrm{K}_{2} \mathrm{SO}_{4}, \mathrm{KNO}_{3}, \mathrm{KCl}$, but we have limited the dust neutralization reactions in this work to calcium to be able to separate the dust-associated water uptake and associated aging from sea salt effects. Since our setup is flexible, the level of aerosol neutralization complexity can/will be changed for other application tasks.

Within GMXe, the aging of dust aerosols depends on the total particle surface area and on the concentrations of the aerosol precursor gases (Pringle et al., 2010). The uptake of gases is kinetically limited considering random motion and diffusion processes that govern the condensation. The rate constant for the condensation on dust particles is given by Eq. (1)

$$
D_{\text {flux }}=\frac{4 \pi D_{f}^{2} r_{\mathrm{w}}}{\frac{4 D_{f}}{v r_{\mathrm{w}} a_{i}}+\frac{r_{\mathrm{w}}}{r_{\mathrm{w}}+z_{f 1}}}
$$

where $r_{\mathrm{w}}$ is the ambient (wet) radius, $D_{f}$ the temperature-dependent diffusion coefficient defined by $D_{f}=0.073 P\left(\frac{T}{T_{\text {ref }}}\right)^{\frac{3}{2}}, P$ the pressure, $T$ the temperature and $T_{\text {ref }}$ the reference temperature $(298.15 \mathrm{~K}), v$ denotes the particle mean velocity, defined by $\sqrt{\frac{8 R_{g} T}{\pi M_{g}}}$, with $R$ the gas constant $\left(8.31 \mathrm{~J} \mathrm{~mol}^{-1} \mathrm{~K}^{-1}\right), M_{g}$ the molar mass, $z_{f 1}$ the mean free path length of the kinetic regime, and $a_{i}$ the accommodation coefficient (Fuchs and Davies, 1989; Seinfeld and Pandis, 2006). In the current setup we use the accommodation coefficients $0.1,0.01$ and 0.01 for sulfuric, hydrochloric and nitric acid, respectively. These values have been empirically determined by comprehensive modeling analysis, which will be presented separately. The uptake of acids is calculated for each particle's size, i.e., for dust for the insoluble accumulation and coarse mode. For the current modeling study though, this setup represents the dust air-pollution dynamics over the eastern Mediterranean well.

To test the relevance of higher resolution simulations for an optimal dust representation in climate models, as emphasized by Gläser et al. (2012), in this study we apply EMAC at the spherical truncations T106 and T255, which correspond to quadratic Gaussian grids in latitude and longitude of approximately $1^{\circ} \times 1^{\circ}$ and $0.5^{\circ} \times 0.5^{\circ}$ (approximately 110 and $50 \mathrm{~km}$ ), respectively, with 31 vertical hybrid pressure levels up to $10 \mathrm{hPa}$. Our model simulation period covers the years 2010 and 2011, in which we focus on two moderate dust events in late September 2011, since at the end of the summer dry season the air pollution build-up reaches a maximum in the EM. The EMAC meteorology is nudged towards ERA-Interim reanalysis data by a Newtonian relaxation data assimilation method to best represent the actual meteorological conditions (Roeckner et al., 2006). The AEROPT submodel is used to calculated aerosol optical depth (AOD), based on internal mixture assumption of different aerosols, using the aerosol information from the GMXe aerosol submodel. The modeled AOD at $550 \mathrm{~nm}$ wavelength is compared to the measured AOD from the sun photometer instruments in the AErosol RObotic NETwork (AERONET) (http://aeronet.gsfc.nasa.gov) over the entire period of the simulation. AERONET (Holben et al., 1998) provides the AOD at different wavelengths $(340,380,440,500,670,870$, $940,1020 \mathrm{~nm}$ ). Only level 2.0 direct sun algorithm wavelengths (cloud-free conditions) are used in this study to calculate AOD at $550 \mathrm{~nm}$ for direct comparison with the modeled AOD following de Meij and Lelieveld (2011) (their Eqs. 1 and 2). In order to increase the number of the calculated $550 \mathrm{~nm}$ data points, we calculate the $550 \mathrm{~nm}$ AOD from different wavelengths starting from closest to $550 \mathrm{~nm}$ depending on the availability of the AERONET data. For instance, the AOD at 500 and $670 \mathrm{~nm}$ wavelengths are used to interpolate to $550 \mathrm{~nm}$. We repeat this procedure for all available wavelengths at each station. For comparison of the time history, the calculated $550 \mathrm{~nm}$ AOD from AERONET is averaged over the model output frequency $(5 \mathrm{~h})$ for a timeconsistent comparison. Additionally, skill scores are used to describe the model performance on a single station scale following Taylor (2001) - their Eq. (4). The skill score accounts for the model bias and variance and helps evaluating the model performance.

\section{Dust-air pollution interaction}

Two distinct dust transport events are the basis of our study of dust-air pollution interactions over the EM. The selected cases represent moderate dust outflow accompanied by air 


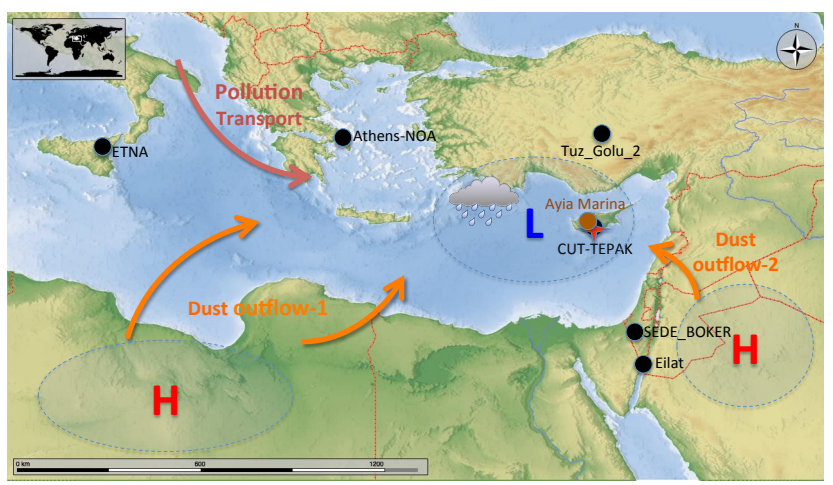

Figure 1. Schematic representation of the prevailing synoptic conditions. Cyprus low, main transport pathways for dust (orange) and air pollution (red) during both dust outflow event to the EM. Observational stations are included: AERONET (black), EMEP station Ayia Marina (brown).

pollution transport from Europe in addition to the local sources of air pollution in the EM. The prevailing synoptic conditions of the EM, schematically shown in Fig. 1, are characterized by a Cyprus low and main transport paths of dust and air pollution to the EM. During both dust events polluted air masses from central and southern Europe are carried into the low-pressure system. Dust event outflow-1 originates from the Sahara and is transported over the EM as a result of the high-pressure system over the Sahara and the lowpressure system over Cyprus. The latter also enhances the transport of air pollution from Europe. Both air pollution and dust are transported over the EM in a frontal system, which is typically associated with precipitation events (Alpert and Ganor, 1993) - shown in the low-pressure area (Fig. 1). During the second event strong winds and a high-pressure system over the Arabian Peninsula resulted in dust transport from the Negev, Sinai and Arabian deserts to the EM (outflow-2). Several measurement stations, used in the study to evaluate the model results, are included in the map (Fig. 1).

\subsection{Long-term model evaluation}

Understanding the interaction between dust and air pollution over the EM requires a realistic representation of aerosols and their precursor gases (e.g., strong acids) in the EMAC model. To evaluate the model setup of our global simulations, we first consider a 2-year simulation at reduced resolution (T106L31, about $110 \mathrm{~km}$ grid spacing).

Figure 2 shows the calculated mean aerosol mass fraction of the fine and the coarse mode for the EMEP station CUTTEPAK in Cyprus. Sulfate (46\%) and ammonium (17\%) dominate the fine mode, while (bulk) sea salt (44\%) and dust (37\%) dominate the coarse mode. Although these model results are shown for Cyprus, they also resemble the aerosol mass fractions obtained during the MINOS campaign (Met-
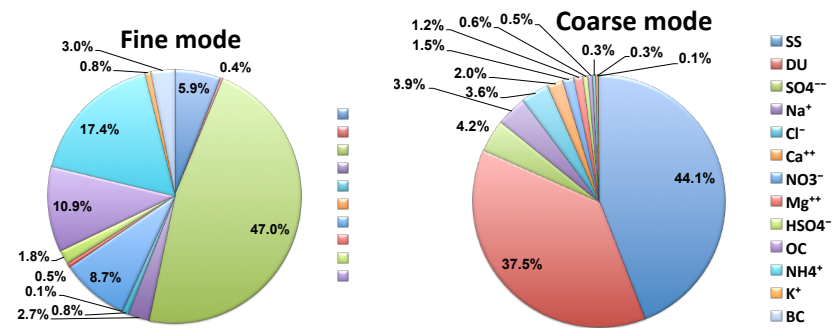

Figure 2. Aerosol mass fractions based on 2 years of model results for CUT-TEPAK in Cyprus.

zger et al., 2006), which was carried out over Crete in the summer 2001 (Lelieveld et al., 2002).

Figure 3 shows monthly average time series of modeled and observed aerosol properties: sulfate, calcium, total (dry) particulate matter $\left(\mathrm{PM}_{2.5}\right)$ at the EMEP station Ayia Marina and the AOD at the AERONET station CUT-TEPAK. The linear distance between the two stations is about $40 \mathrm{~km}$ and both are located in one model grid box at T106 resolution. Generally, the EMAC results compare well with these observations. The model captures the seasonal variability of sulfate, although the highest concentration during summer and early autumn are somewhat too low. EMAC seems to underestimate the high production yields of sulfates during summer, which mainly results from the oxidation of the precursor gas $\mathrm{SO}_{2}$, enhanced by the prevailing subsidence of air over the EM region. For calcium, the model captures the concentration peaks, which correspond to the dust outflow into the Mediterranean from both the Saharan and Arabian deserts during the spring season. Capturing the peak concentrations of calcium shows the capability of EMAC to simulate the dust outflow throughout the year. Furthermore, simulated total PM also shows good agreement with the observed concentrations and the seasonality. However, the model captures the seasonality of PM in the year 2011 better than in 2010, partly related to the model spin-up time in this year. The PM is the total (dry) mass of all aerosols considered in this setup, and is explicitly calculated from aerosol microphysics and thermodynamics as described in Pringle et al. (2010). These results are supported by the AOD comparison, corroborating that EMAC captures the observations. Considering that the PM and AOD are two independent observations, in addition to the independent species sulfate and calcium, these results confirm that this model configuration is capable of simulating the major aspects of atmospheric composition needed to study the interaction between dust and air pollution.

\subsection{EMAC case study}

An episode of low visibility occurred over Cyprus in late September 2011 as a result of increased atmospheric dust concentrations. Two dust events were reported; the first event started on 20 September and originated in the Sahara while 

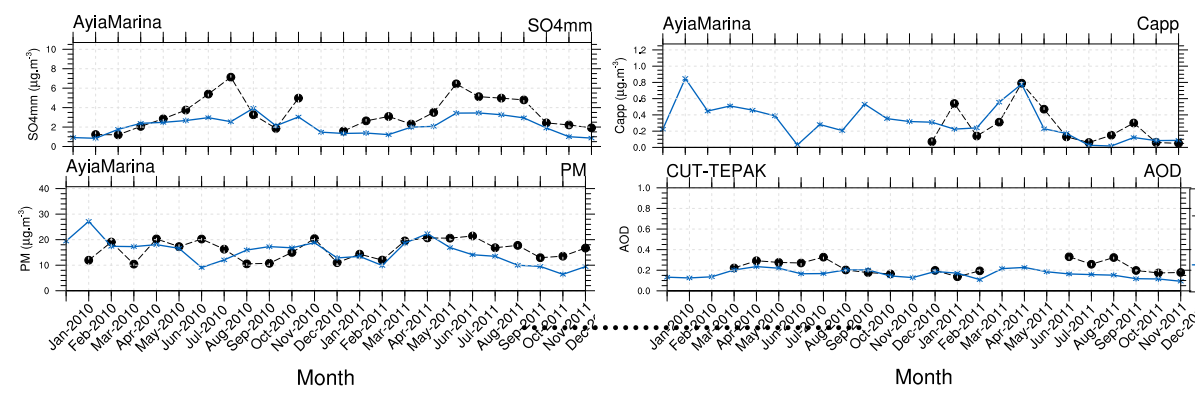

$\cdot \bullet \cdot$ Observations

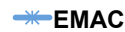

Figure 3. EMAC (T106L31) results (blue line): Aerosol sulfate $\left(\mathrm{SO}_{4}^{2-}\right)$, calcium $\left(\mathrm{Ca}^{2+}\right)$, total particulate (dry) matter (PM) and AOD $(550 \mathrm{~nm})$ compared to observations (black circles) at the EMEP station Ayia Marina and the AERONET station CUT-TEPAK in Cyprus, 2010-2011 (monthly means).
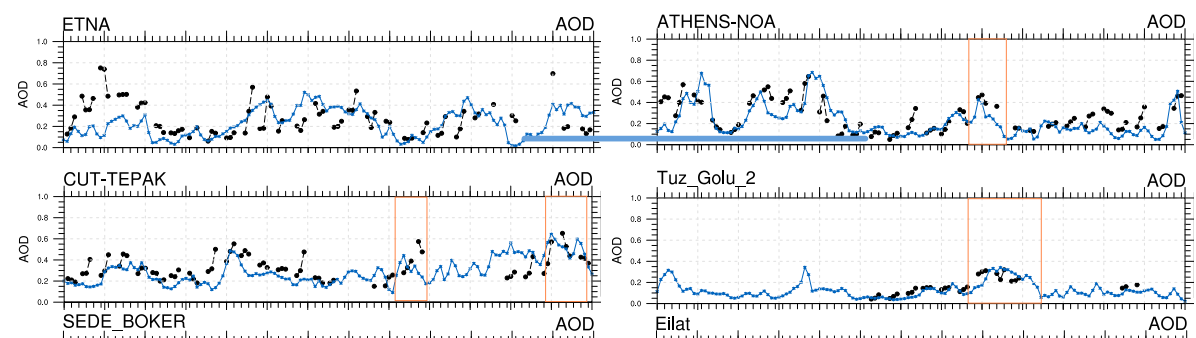

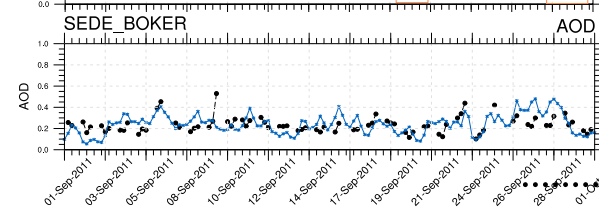

Time

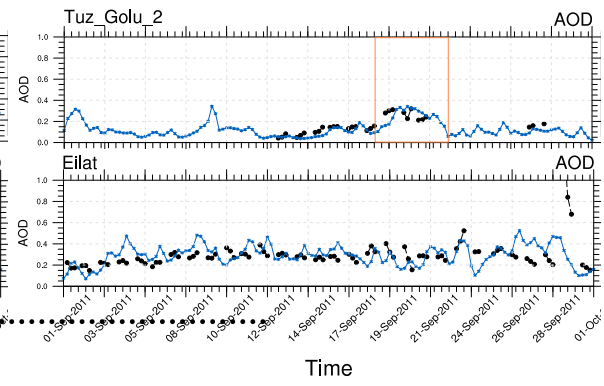

*EMAC

Figure 4. EMAC (T255L31) model results (blue line) of AOD $(550 \mathrm{~nm})$ and AERONET observations (black dots). The orange boxes delineate the dust outflow events.

the dust was removed mainly by precipitation over Cyprus. The second event started on 26 September from the Arabian deserts and the dust was transported over the EM and removed mainly by dry deposition. The two episodes are investigated using the high resolution model version (T225L31, about $50 \mathrm{~km}$ grid spacing), using the same EMAC setup mentioned above.

\section{Aerosol optical depth}

Figure 4 shows the AOD time series over six AERONET stations in the eastern Mediterranean and Middle East region in September 2011, which capture the selected dust episode. The periods of the two dust outflow events are delineated (orange box in ATHENS-NOA, CUT-TEPAK and Tuz_Golu_2 stations). In general, the model reproduces the variability and magnitude of the AOD observations in the EM region. During the first dust event (17-22 September 2011), the modeled and observed AOD are about 0.4 in the dust outflow region, which extends to Athens-NOA and Tuz_Golu_2. At CUT-TEPAK the observed AOD of 0.6 is higher and slightly above the modeled AOD. At Sde Boker and Eilat, closer to the dust source area for the dust outflow- 2 event, the model results are in good agreement with the observations. Eilat, however, is strongly impacted by local sources during the second dust event and the observed AOD up to 1.0 is underestimated by the model, despite the relatively high model resolution ( $50 \mathrm{~km}$ grid box). Eilat is located at the coast in a valley between mountain ranges in Egypt, Jordan and Israel. The model may not capture the magnitude of the dust AOD but does reproduce the variability at this station, despite the complexity of the terrain at the Eilat site for which our $50 \mathrm{~km}$ model resolution might be too coarse. Possibly some of the high AOD is explained by local coarse-mode dust particles that rapidly sediment and contribute little to long-distance transport. Figure 5 shows the AOD (monthly mean) over the EM region during September 2011, including AERONET observations and corresponding skill scores. The comparison indicates good agreement with skill scores above 0.5 , while the model tends to slightly underestimate the AOD. Both the model and observations show similar AOD patterns for this 

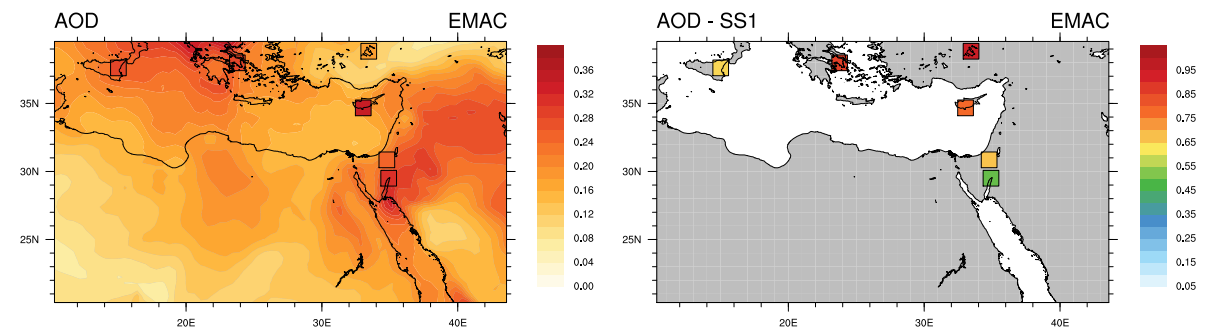

Figure 5. EMAC (T255L31) model results of AOD $(550 \mathrm{~nm})$ for September 2011 (left) and skill score (right). The six AERONET stations of Fig. 4 are included (squares).

month, which increase eastwards. The highest skill scores are, however, achieved at ATHENS-NOA, Greece (0.8) and Tuz_Golu_2 (0.9), Turkey. In the Negev and Arabian deserts AODs are highest due to strong emissions at this time, which is captured well by the model. In addition, where the primary dust is the dominant aerosol (in EMAC), the model AOD compares better with observations than at locations that are affected by aged dust, e.g., over Cyprus (CUT-TEPAK). Generally, stations with aged dust particles show reduced agreement with observation. In addition to the aerosol dust loading (number and mass concentrations), the relative humidity and aerosol composition (e.g., as a function of air pollution) become important, as both determine the aerosol water uptake, which in turn affects the AOD.

\subsection{Dust outflow characteristics}

The true color image from the Moderate Resolution Imaging Spectro-radiometer (MODIS) Aqua instrument, Fig. 6, shows both dust events over the EM. Figure 7 shows the daily average, vertically integrated dust load over the EM region for both dust events and HYSPLIT (http://ready.arl. noaa.gov/) backward trajectories, which show the pathways of the air masses that reached the CUT-TEPAK station on 22 and 28 September 2011. The HYSPLIT trajectories are driven by NCEP (National Center for Environmental Prediction) reanalysis data that appear to be consistent with our model calculations. The streamlines and the velocity vectors refer to an elevation of about $2.5 \mathrm{~km}(700 \mathrm{hPa})$ and show the maximum dust concentration during atmospheric transport. In the dust outflow-1 event (Fig. 7, upper panels) the lowpressure system (not shown here) over Cyprus resulted in cyclonic activity that enhanced dust transport from the Sahara and air pollution and moisture transport from central and southern Europe. The cyclonic activity of 21 September then advected eastwards. The backward trajectories show that air masses reached the CUT-TEPAK station at different times from different sources; air masses carrying dust from Egypt and from Tunisia. The air masses from Egypt started at a lower elevation and were then lifted during transport across the Mediterranean, while the dust from Tunisia was transported over a long distance and at higher eleva-

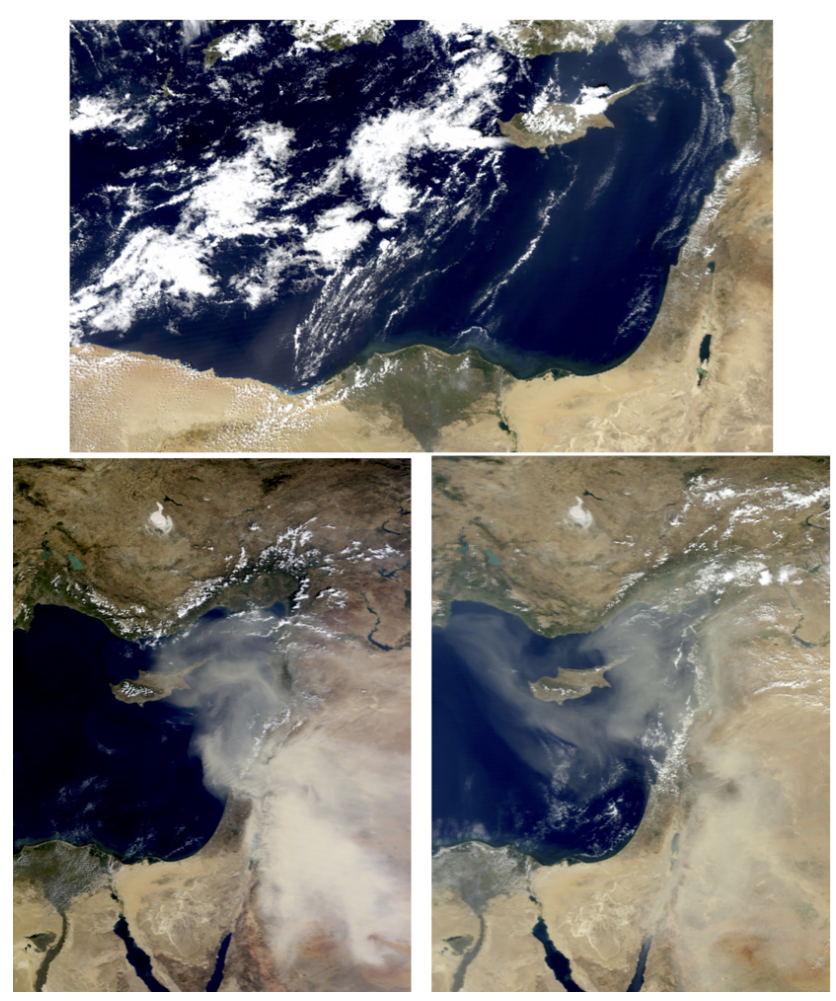

Figure 6. MODIS Aqua true color image (top) for 22 September (11:10 UTC overpass time) with clouds and dust outflow from Libya to the EM. Bottom: MODIS-Terra true color images: (left) 28 September 2011 (08:55 UTC overpass time), (right) 29 September 2011 (08:00 UTC overpass time) with dust outflow from the Negev and Arabian deserts to the EM.

tions. Polluted air masses, originating in continental Europe, reached CUT-TEPAK somewhat later in time. Typically, different air masses from different sources converged over CUTTEPAK at $1.5 \mathrm{~km}$ altitude. Interestingly, dust from the Sahara is mixed with air pollution from Europe over Cyprus and the EM region. During the dust outflow-2 event (Fig. 7, middle panels) dust was emitted as a result of the strong surface winds (not shown) in the Negev and Arabian deserts and then transported to the EM according to the pressure gradients in the following days. This is confirmed by the backward 

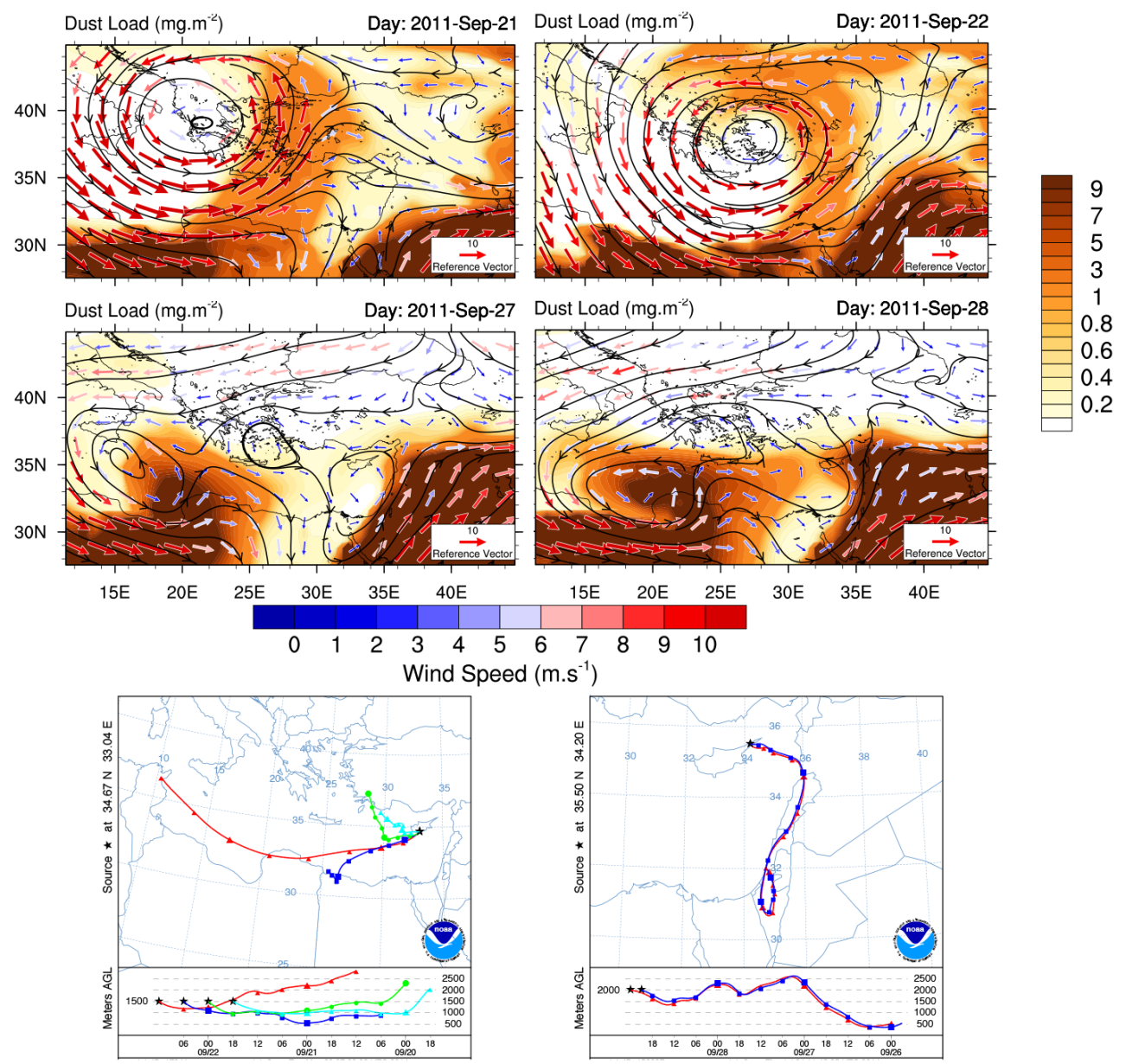

Figure 7. Daily average dust load over the eastern Mediterranean and HYSPLIT model backward trajectories ending at 12:00 UTC 22 September at the CUT-TEPAK station and 21:00 on 28 September 2011 at $35.5^{\circ} \mathrm{N}$ and $34.3^{\circ} \mathrm{E}$ for both dust outflow events.

trajectories which show the dust pathways. The dust reached Cyprus with the highest concentration on 28 September. By 29 September the dust was largely removed from the atmosphere. Typically, Europe is a main source of air pollution that is transported to the EM, usually at higher concentrations than in transport from the Middle East (Lelieveld et al., 2002). As a result, the Saharan dust outflow is more strongly mixed with, and subsequently chemically aged by European air pollution, compared to the Arabian dust outflow.

\subsubsection{Dynamical and vertical structure (EMAC results)}

In the outflow- 1 class of events, dust is typically transported from the Sahara to the Mediterranean and then to the EM by Sharav cyclones (Goudie and Middleton, 2006; Ganor et al., 2010), associated with a cold front and often accompanied by rain (Alpert and Ganor, 1993). The model indeed simulates such a frontal system that carries the dust from the Sahara to the EM region (Fig. 8). Velocity vectors are shown at the elevation where the maximum dust concentrations occur during transport. The vertical cross sections at the latitude of the CUT-TEPAK station show the vertical extent of the dust outflow with a maximum concentration at $2.5 \mathrm{~km}$ a.s. 1 . (above sea level). As shown in the figure, the dust moved eastward at this elevation and the dust loading is significantly reduced as the frontal system passed through. The model simulation further shows that the dust is efficiently removed by the precipitation event on 22 September between 06:00 and 15:00 LT, which will be described in more detail below. For the dust outflow-2 event, Fig. 9 shows time series with enhanced dust loading over the EM region. The main dust source is located in the Negev and northern Saudi Arabian deserts, with additional dust originating in the eastern Sinai in Egypt. As a result of the strong surface winds during this period, dust was emitted from this area and transferred to the $\mathrm{EM}$ at about $2.5 \mathrm{~km}$ a.s.l. in the following days. As shown in Fig. 9, the dust reaches Cyprus with the highest concentration on 28 September. The cross sections show that the dust is lifted up as high as $6 \mathrm{~km}$ altitude with a mass concentration of $1 \mu \mathrm{g} \mathrm{m}^{-3}$, compared to the maximum height of $2.5 \mathrm{~km}$ (same concentration level) in the outflow-1 event. This could result from the prevailing subsidence over the Mediterranean, 

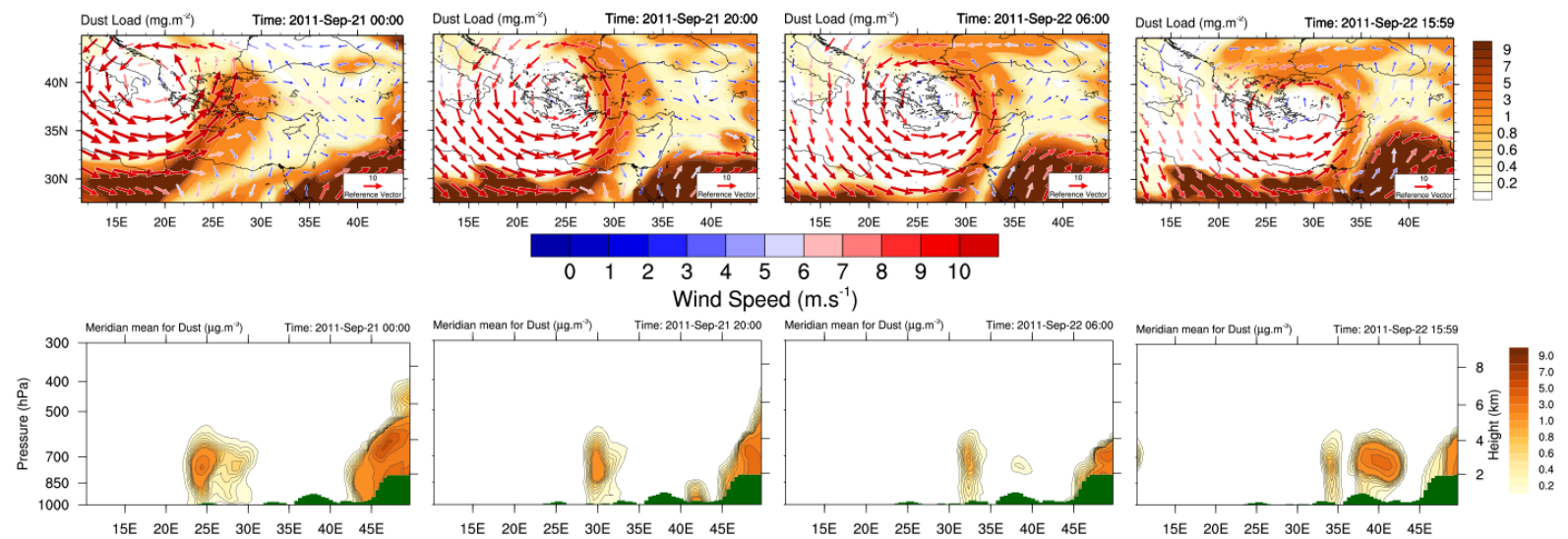

Figure 8. Time series of (top) dust load and (bottom) meridional mean for the first event at CUT-TEPAK location $\left(34.675^{\circ} \mathrm{N}\right)$. The green shaded area represents the orography.
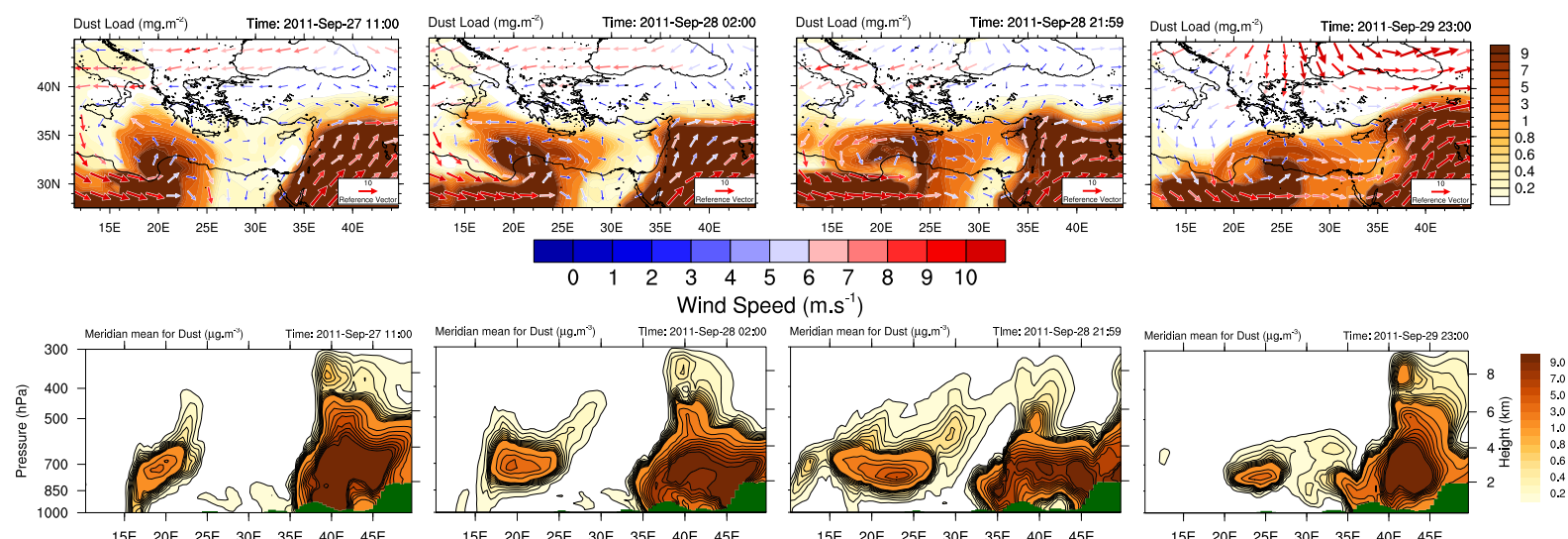

Figure 9. Time series of (top) dust load and (bottom) meridional mean for the second event at CUT-TEPAK location $\left(34.675^{\circ} \mathrm{N}\right)$. The green shaded area represents the orography.

which prevents the Saharan dust from penetrating to higher altitudes. In contrast, the outflow- 2 event is accompanied with strong convective activity over Arabian deserts, which lifted the dust to higher altitudes. The cross sections in Fig. 9 show that the dust transport from the Middle East occurred at higher elevations than that from the Sahara.

\subsubsection{EMAC versus ground based lidar profiles}

The vertical structure of the dust outflow-2 is compared to ground-based lidar measurements of the Cyprus University of Technology (CUT) in Limassol, Cyprus, which also hosts the AERONET station. The lidar observations have been recently used to study dust outflows over the EM, including the dust outflow-2 considered in our study (Mamouri et al., 2013; Nisantzi et al., 2014; Mamouri and Ansmann, 2014, 2015). For consistent comparison, the lidar observations are averaged within the model vertical grid box.
Figure 10 shows the simulated and observed total and dust only extinction at CUT-TEPAK. The model results are shown at three different longitudes: $33^{\circ} \mathrm{E}$ at CUT-TEPAK (EMAC), $34^{\circ} \mathrm{E}$ (EMAC-1) and $35^{\circ} \mathrm{E}$ (EMAC-2), with all longitudes referring to the latitude of the CUT-TEPAK station $\left(34.675^{\circ} \mathrm{N}\right)$. The comparison shows that EMAC captures the lidar signal, but $2^{\circ}$ (about $200 \mathrm{~km}$ ) more to the east. This underestimation decreases with each profile further east, indicating a steep gradient of the model dust layer concentration that is associated with the front of the dust outflow-2 (shown in Figs. 6 and 7). Although the magnitude of the model extinction is predicted lower at the CUTTEPAK station at both days, EMAC captures the observed peak at $1.5 \mathrm{~km}$ height (second day) with a $1.8 \mathrm{~km}$ dust layer peak height well, given the relatively coarse vertical grid resolution of the model (which is $500 \mathrm{~m}$ at that height).

Interestingly, the calculated vertical extent of the dust layer is wider than the lidar signal, which indicates that the total aerosol layer is thicker, at least a few hundred kilometers eastward. This might be related to flow disturbance by the 

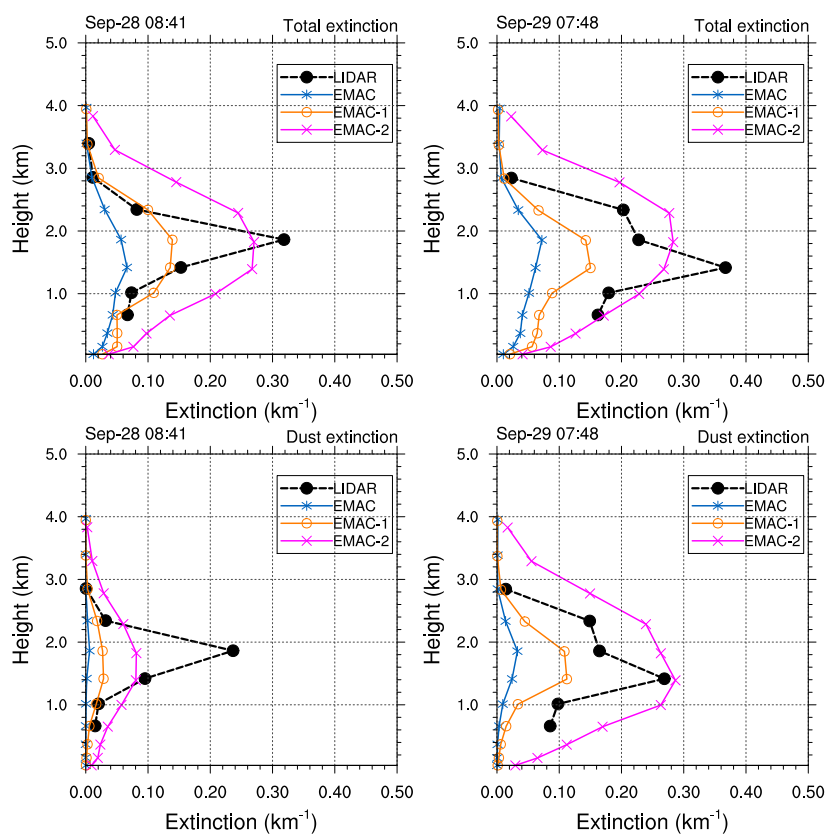

Figure 10. Comparison between the modeled and the observed total and dust only extinction coefficient at CUT-TEPAK lidar station at different longitudes: $33^{\circ} \mathrm{E}$ (EMAC) at CUT-TEPAK station, $34^{\circ} \mathrm{E}$ (EMAC-1) and $35^{\circ} \mathrm{E}$ (EMAC-2); all longitudes refer to the latitude of CUT-TEPAK $\left(34.675^{\circ} \mathrm{N}\right)$.

orography, and/or a result of the contribution of other compounds that are considered in our model simulation. The vertically integrated dust extinction is similar to the total extinction profiles for both EMAC and the observations, but the predicted concentration maximum of the dust layer is closer to the observations for the second day. For the first day, EMAC does not capture the observed dust signal, but the total AOD (integral of the area under the profile) is comparable to the AERONET AOD shown in Fig. 4 for both days.

\subsubsection{EMAC vs. CALIPSO retrieved vertical structure}

To study the vertical structure of the dust outflow- 1 event, the Cloud-Aerosol Lidar and Infrared Pathfinder Satellite Observation (CALIPSO) Level 2 version 3.01, $5 \mathrm{~km}$ aerosol profile (APro-Prov) product is used. Unfortunately, no CALIPSO data are available for the outflow- 2 case. CALIPSO is a space-borne lidar instrument that provides 2-D vertical distributions of atmospheric aerosols at $5 \mathrm{~km}$ horizontal resolution and $30-180 \mathrm{~m}$ vertical resolution. CALIPSO data retrievals discriminate aerosol layers from clouds and categorizes the particles according to six subtypes (dust, marine, smoke, polluted dust, polluted continental and clean continental), while the observations show the best agreement with AERONET products for dust-dominated regions (Schuster et al., 2012). Regardless of the CALIPSO uncertainties in retrieving different dust cases, the correlation coefficients are with about 0.58 higher compared to the other aerosol types (Schuster

et al., 2012). In addition, the CALIPSO aerosol type classification could overestimate the extinction and the optical depth for marine aerosols. This may add artifacts to the mixed dust classification over land (Kanitz et al., 2014). Therefore, the CALIPSO data is particularly useful to study the vertical distribution and transport of atmospheric dust (Liu et al., 2008; Uno et al., 2011; Su and Toon, 2011; Johnson et al., 2012). The EMAC calculated dust concentrations and the corresponding extinction are interpolated in space and time to the CALIPSO tracks.

Figure 11 shows two CALIPSO tracks, following the satellite overpass time from left to right. The overpass time is shown in the track name in the upper left corner of each figure. Also included in the upper panels are the scatter plot comparisons between modeled and observed dust extinction, colored by the height of each observation point. In the main figures, the solid black contours represent the modeled dust extinction and the colored areas represent the CALIPSO extinction observations. The upper panels show the extinction of dust only from both model and CALIPSO, the lower panels include the extinction of all aerosols excluding dust (brown-dotted line), the dust extinction (black line) and the CALIPSO aerosol subtype and cloud classifications. As shown in the upper panel of Fig. 11, the model captures the spatial variability, i.e., the horizontal and vertical extents of the dust plume in both tracks. In particular the height of the dust plume is captured well by the model, which is a critical parameter for determining the dust lifetime in the atmosphere (Levin et al., 2005). The scatter plot shows that the model somewhat underestimates the dust extinction at higher altitudes and overestimates it at lower altitudes. The best agreement is found at the peak concentration of the dust plume, between 2000 and $3000 \mathrm{~m}$.

For both cases, the model and CALISPO results show that the dust concentration decreased during the transport and the height of the dust plume decreased from about $4000 \mathrm{~m}$ over the central Mediterranean on 21 September to about $2000 \mathrm{~m}$ over the EM on 22 September. The model results showed that the dust loading has significantly reduced after the frontal system has passed (Fig. 8) which enhanced the dust deposition (see next section). Concerning the aging of the dust particles during transport, the model and CALIPSO results indicate less interaction between aerosol types and dust aging over North Africa compared to the Mediterranean, where usually stronger mixing between dust and air pollution occurs. This is indicated by many studies (Levin et al., 1996, 2005; Lelieveld et al., 2002). Air pollution in the EM consists of aerosol precursor gases (such as sulfuric, hydrochloric and nitric acid, ammonia) which can directly condense or form semi-volatile compounds on the dust surface (Metzger et al., 2006). The degree of dust aging is indicated by the differences between the black- and brown-dotted contour lines, and by the CALIPSO classifications. Over the Mediterranean, from latitudes higher than $30^{\circ} \mathrm{N}$, aging of dust is observed from both model (black- and brown-dotted contours) 

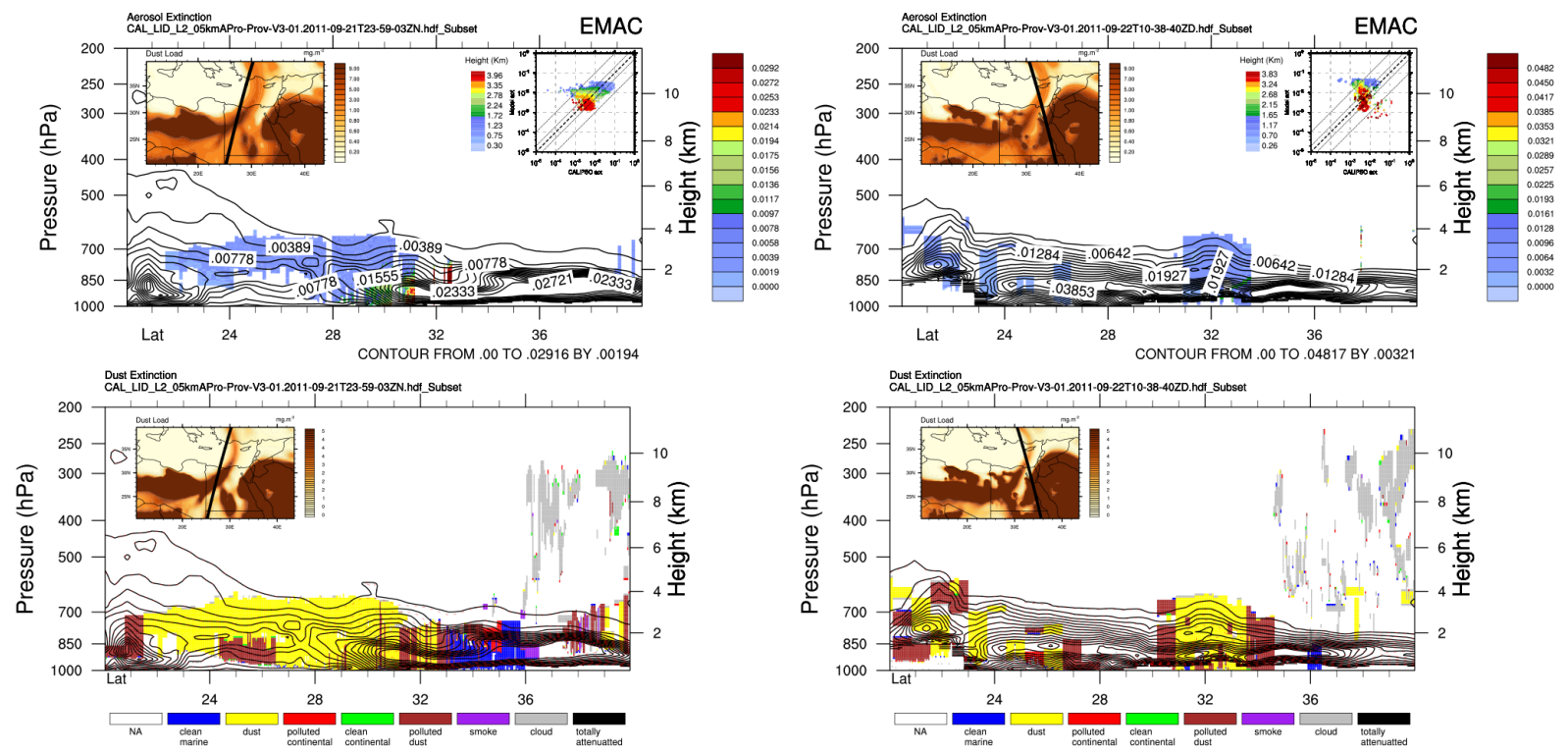

Figure 11. Collocated EMAC calculations and CALIPSO observations of extinction and dust load for two different CALIPSO tracks during the first dust outflow event - overpasses from Africa to the EM, (top) dust extinction (bottom) CALIPSO aerosol classifications, dust extinction (black line) and total extinction (brown dotted line).
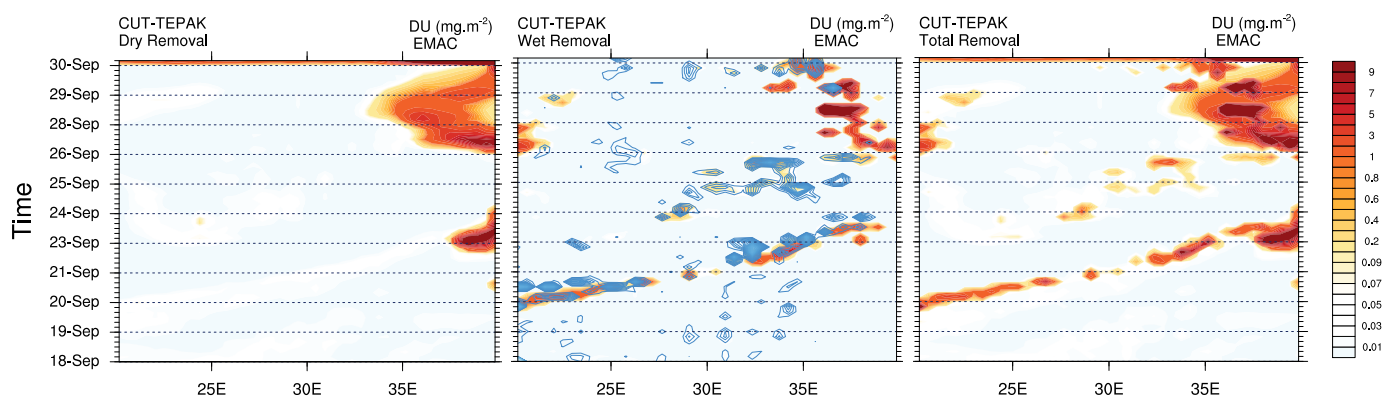

Figure 12. Time evolution of dry, wet and total removal of dust at CUT-TEPAK; (blue) TRIMM observations, (orange) EMAC precipitation (see text).

and CALIPSO classifications (which subsequently shows smoke, polluted dust, polluted continental). The CALIPSO classification "polluted dust" may cover cases where dust is mixed with other aerosols, but not necessarily chemically aged. With the current CALIPSO version 3.01 algorithm, it is not possible to distinguish between dust mixing and dust aging by air pollution. In such cases, polluted dust may represent aged dust. The comparison with our model results can help distinguish between the types of aerosol extinction.

\subsubsection{Dust removal}

To evaluate the dust scavenging and precipitation over the EM we use the Tropical Rainfall Measuring Mission (TRMM) level-3 (collection 3B42) 3-hourly product (http:// pmm.nasa.gov/TRMM). Figure 12 shows the time evolution of the dust removal by wet and dry deposition mechanisms as well as the total dust removal at the surface. The blue contours show the TRMM precipitation observations at the surface with the modeled dust removed by wet scavenging overlaid. As shown in the figure, starting from 20 September, the dust was mainly removed by scavenging associated with strong precipitation. The precipitation events started on 20 September at $20-40^{\circ} \mathrm{E}$. The figure shows that the calculated wet dust scavenging largely coincides with the observed precipitation; however the model may overestimate wet scavenging of the dust. Dry removal was insignificant for the dust outflow-1 event. On 23 September the dust concentration decreased over the area from 35 to $50^{\circ} \mathrm{E}$ as a result of dilution during the dissolution of the low-pressure system developed over the region. In the outflow- 2 event the dust was largely removed from 26 September onward, which explains the increase of the dust concentration at the surface due to particle sedimentation from elevations above $2 \mathrm{~km}$. The efficiency of the wet dust scavenging depends strongly on the aged dust fraction; by increasing the soluble dust fraction the wet dust 

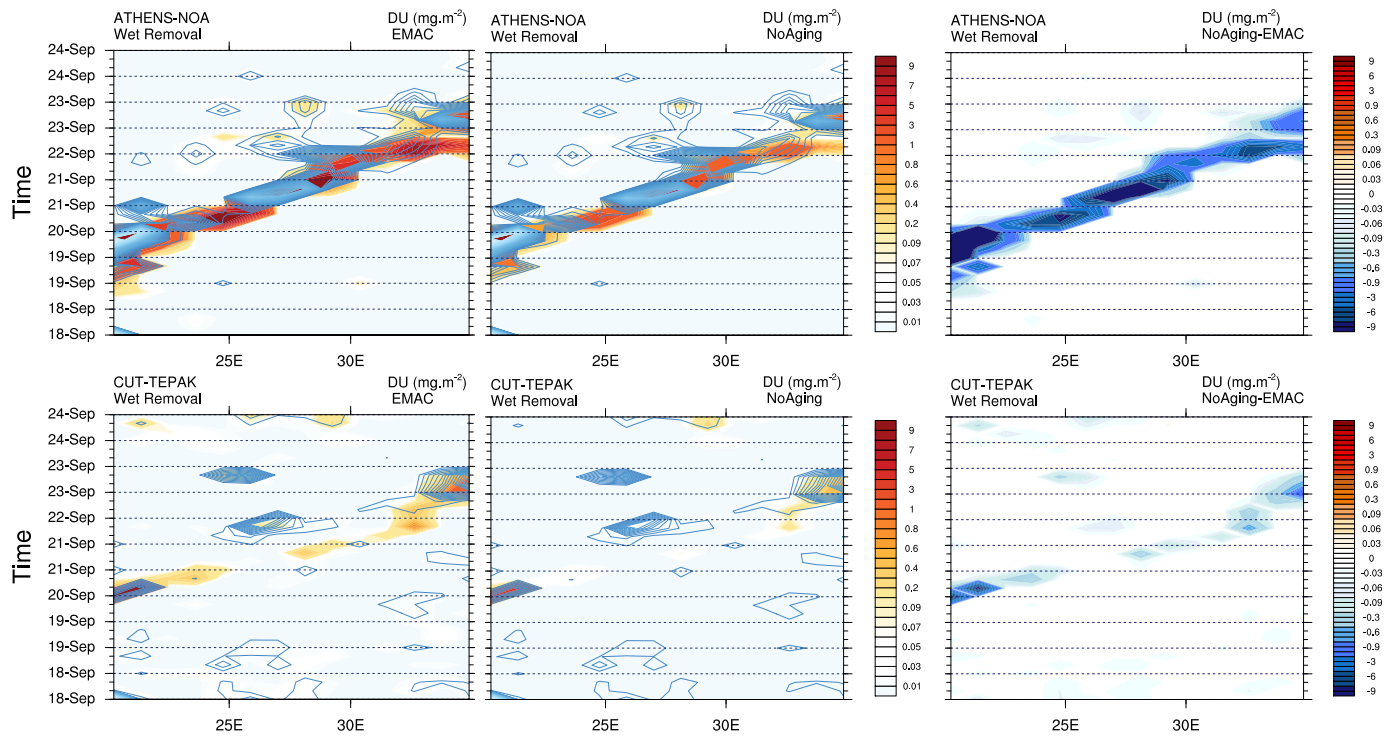

Figure 13. Time evolution of wet dust removal at the CUT-TEPAK and ATHENS-NOA stations for two simulations considering aged dust (EMAC) and non-aged, pristine dust particles (NoAging); (blue) TRIMM observations, (orange) EMAC precipitation (see text).

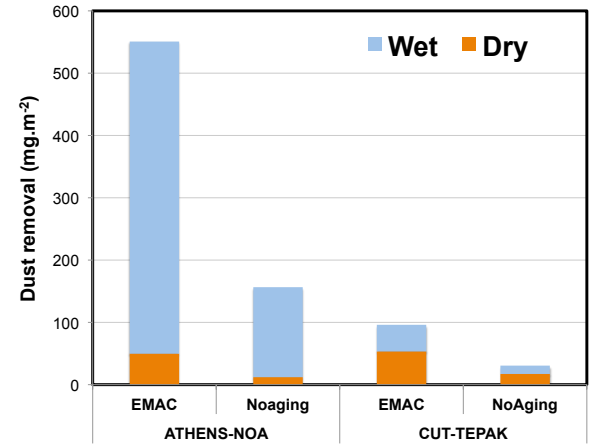

Figure 14. Sensitivity of dust removal (wet and dry) to dust aging: integrated dust removal over the period from 18 to 24 September 2011.

scavenging increases, since aged dust particles can be more efficiently taken up by cloud droplets (Teller et al., 2012). This is captured by our model setup which employs the comprehensive scavenging mechanism of Tost et al. (2006).

\subsection{Dust removal sensitivity to dust aging}

During the outflow- 1 event the dust is efficiently removed by precipitation over the EM as a result of mixing of African dust with air pollution from Europe. This results in reduction of the AOD from 0.5 to 0.05 at the ATHENS-NOA station (Fig. 4). To study the impact of dust aging on the removal efficiency, it was switched off in a sensitivity simulation for which the condensation of soluble compounds on dust particles has been excluded. This results in wet dust removal by impaction scavenging only, while nucleation scavenging is not considered (Tost et al., 2006). Figure 13 shows the time evolution of wet dust removal for the aged and non-aged (hence pristine) dust cases at cross sections passing over two different stations, ATHENS-NOA and CUTTEPAK. The TRMM precipitation observations are overlaid. The right panels of the figures show the differences between the wet dust removal at the surface for both cases. The TRMM precipitation and dust removal in Fig. 13 differs from Fig. 12 as a result of different model resolutions (T106 and $\mathrm{T} 255$, respectively). The differences in the TRMM precipitation between Figs. 12 and 13 results from regridding of the TRMM precipitation ( $25 \mathrm{~km}$ resolution) to the model resolution $(50$ and $110 \mathrm{~km})$. The dust removal by the higher model resolution, Fig. 12, resolves the observations better in space and time (note the slightly different time axis used to focus on the dust outflow-1 event).

Figure 13 shows that the wet dust removal is simulated realistically in space and time at both stations, compared to the TRMM observations. The aged and non-aged cases show significant difference in the wet dust removal. Obviously, an additional amount of the dust is removed due to aging processes (EMAC results) as a result of mixing with air pollution from Europe. The average difference in the wet dust removal is $10 \mathrm{mg} \mathrm{m}^{-2}$ at ATHENS-NOA and twice as much dust is removed in the case of aging. At CUT-TEPAK, the dust concentration in the atmosphere is lower due to removal processes during transport, and also because of less precipitation compared to the TRMM observations at ATHENS-NOA. This results in stronger wet dust removal at ATHENS-NOA than at CUT-TEPAK. Figure 14 shows the total time integral of the dust removal for CUT-TEPAK and ATHENS-NOA as shown in Fig. 13. The total dust removal for the case of aging (labeled "EMAC") is generally higher than by switching 

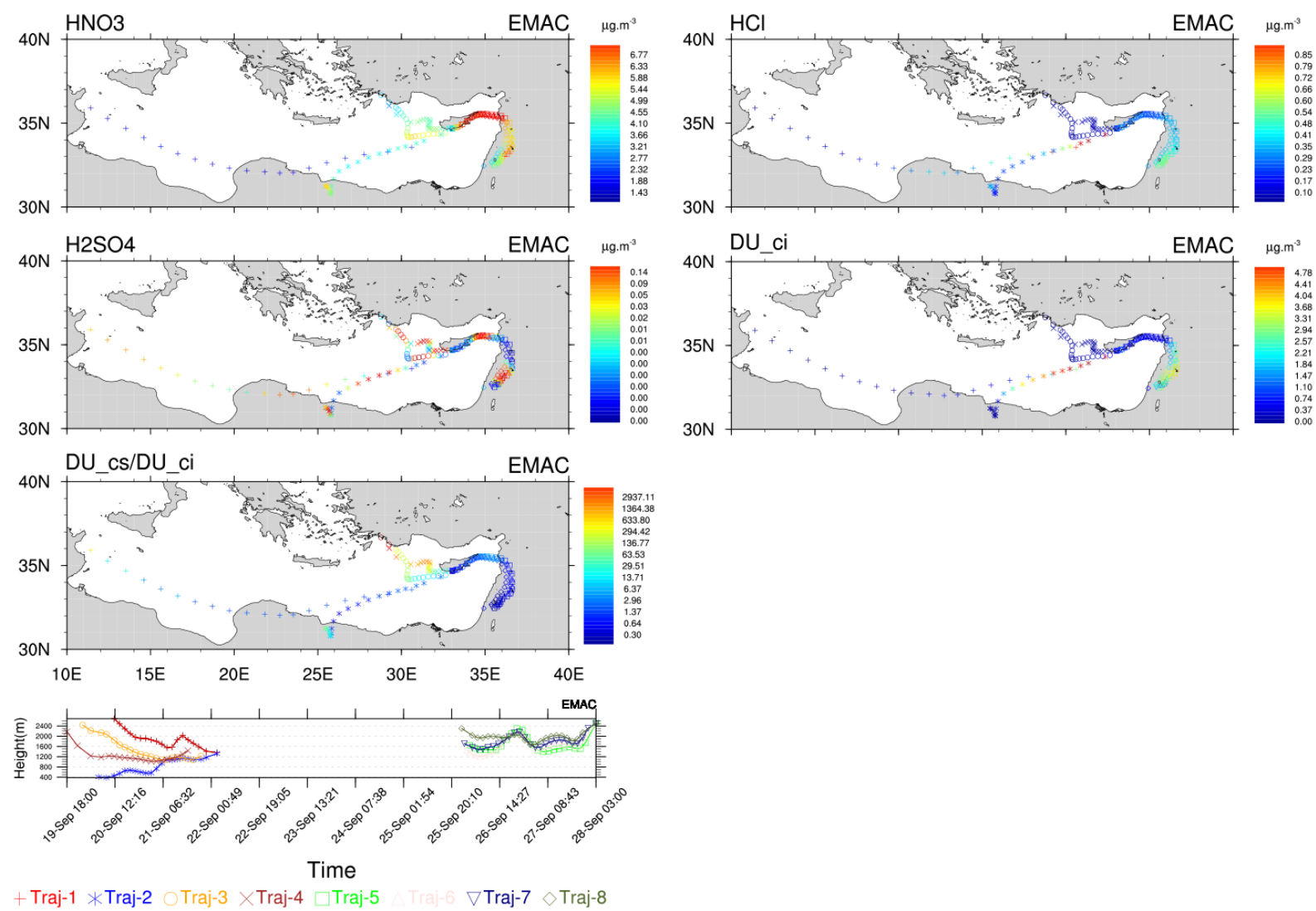

Figure 15. Sampled model concentrations for both dust outflow events; $\mathrm{HNO}_{3}, \mathrm{H}_{2} \mathrm{SO}_{4}$, $\mathrm{HCl}$, insoluble (pristine) dust fraction (DU_ci) and the aged dust proxy, ADP (DU_cs / DU_ci).

off the aging (labeled "NoAging"). This effect is more pronounced for the wet removal than for the dry deposition. Dry removal is enhanced in the case of aging due to the condensation of additional soluble compounds on the originally insoluble dust particles, which increases their size and weight and shifts them to the soluble mode. This inter-modal shift results in higher wet removal by the subsequent nucleation scavenging. In EMAC, the latter acts on dust particles which are only in the soluble mode and which are, if present, aged by definition (in our setup). In contrast to the dry deposition, the ratios between the aging and non-aging cases are much higher for ATHENS-NOA than for CUT-TEPAK, which is mainly a result of the different dust loadings. As a result, the difference between the aged and non-aged is less significant at CUT-TEPAK compared to ATHENS-NOA. This suggests that during the transport from Africa to the EM region, aging largely determines the dust and air pollution lifetime over the EM.

\subsection{Aged dust proxy (ADP)}

To identify the dust-air pollution interactions, back trajectories of various model aerosol concentrations have been sampled along HYSPLIT back trajectories for both dust out- flow cases, i.e., sulfuric, nitric and hydrochloric acid, insoluble coarse-mode dust (DU_ci) as shown in Fig. 15. For the dust outflow-1 event four trajectories are calculated (Traj-1 to Traj-4), which represent the air masses arriving from the Sahara and Europe. For the dust outflow-2 event air masses originated over the Negev and Arabian deserts, as shown by Traj-5 to Traj-8. Different colors refer to the concentrations, while the marker types refer to different trajectories. Additionally shown is the ratio between the coarse-mode soluble (DU_cs) and insoluble (DU_ci) dust mass fraction, which can be regarded as an aged dust proxy (ADP). The ADP is introduced to illustrate the aging mechanism in EMAC. In our EMAC aerosol setup, dust is originally emitted only in the insoluble accumulation (DU_ai) and coarse mode (DU_ci). Upon aging, which requires the condensation of strong acids, the aged dust fraction is transferred to the corresponding soluble mode, e.g., DU_ai to DU_as and DU_ci to DU_cs, whereby DU_as can further grow into DU_cs, as a result of aerosol hygroscopic growth or coagulation (Pringle et al., 2010). Thus, a low ADP indicates freshly emitted dust which is not aged, while high ADP values indicate aged dust. For very high ADP values, dust has been subject to long-range transport with significant aging, since practically all insoluble dust has been transferred into the soluble mode. This 
is the case north and west of Cyprus, where dust becomes strongly polluted during both dust events.

The dust concentration shows an increasing tendency along the Traj- 1 and Traj- 2 as they reach Cyprus. This results from the actual dust supply from the dust emission sources along Traj-2, which originates in Libya. Traj-3 and Traj-4, which originate in Europe, show very low dust concentrations, due to the absence of dust emission sources in southern Europe (in EMAC). However, the trajectories of sulfuric and nitric acid show instead an increasing tendency along Traj-3 and Traj-4. The low-pressure system over Cyprus during the second dust event enhanced the transport of different aerosols and gases to the EM. The relatively low wind speed within the low-pressure system, shown in Fig. 9, increased the residence time of pollution and dust, and allowed extended mixing and efficient dust aging. As a result, dust particles have been successively coated by different soluble compounds, which increases the ADP over time as the air masses approach Cyprus from the west (Traj-1 to Traj-4). Note that the ADP is higher for Traj-3 and Traj-4 due to the lower insoluble dust (DU_ci) concentration along these trajectories compared to Traj-1 and Traj-2. For the dust outflow2 event, the ADP is much lower compared to the outflow-1 event since the dust does not encounter much air pollution from Europe and thus ages less effectively. Interestingly, as long as the sulfuric and nitric acid concentrations increase along Traj-5 to Traj- 8 over the Mediterranean, the ADP increases from about 1 to 13 . This underscores the strong interaction between the dust and air pollution over the EM due to the relatively high air pollution concentrations.

\section{Conclusions}

Interactions of dust and air pollution over the EM have been studied, focusing on two distinct dust transport events on 22 and 28 September 2011, using the atmospheric chemistryclimate model EMAC at relatively high spectral resolution (T255L31, about $50 \mathrm{~km}$ grid spacing). At lower resolution (T106L31, about $110 \mathrm{~km}$ grid spacing), in an extended 2year simulation (2010-2011), the model performs reasonably well in simulating the PM and AOD over the EM, while at high resolution the model results closely agree with the observations. Concentrations of calcium cations, used as a proxy for dust reactivity, show good agreement with groundbased observations. The model captures the AOD at different AERONET stations in the region, however, with some underestimation at the CUT-TEPAK station in Cyprus, coincident with relatively strong aging and efficient removal of the dust.

Both simulation results and backward trajectory analysis show that the development of a synoptic low-pressure system over the EM enhances the dust transport from the Sahara along the cold front, which also carries dust from the Negev and Arabian deserts as well as air pollution to the EM. The model reproduces the frontal system and the associated precipitation. Our results show that the Saharan dust was mainly removed by precipitation, which is captured well by the model, consistent with observations. Generally, EMAC captures the dust transport in both cases, and the vertical structure of dust layers is reproduced accurately by the model, confirmed by CALISPO satellite observations. Also the mixing of dust with air pollution over the EM is captured well by the model compared to the CALIPSO observations and aerosol classifications. Both EMAC and CALIPSO show that the mixing between dust and air pollution can be very efficient over the Mediterranean.

The model results indicate that the dust is aged, especially from the Sahara and to a lesser degree from the Negev and Arabian deserts. The level of aging depends mainly on the mixing time between dust and air pollution and concentrations of the latter. The longer travel period for Saharan dust therefore results in more efficient aging compared to Arabian dust arriving in the EM, illustrated by a newly introduced aged dust proxy. Based on a sensitivity study we find that the mixing of air pollution and dust enhances nucleation scavenging, resulting in 3 times more rapid dust scavenging compared to non-aged (pristine) dust, while uptake of pollution and consequent hygroscopic growth also enhances sedimentation and dry deposition. Our study suggests that the aging of dust over the EM can significantly decrease the dust lifetime and atmospheric loading.

\section{The Supplement related to this article is available online at doi:10.5194/acp-15-9173-2015-supplement.}

Acknowledgements. All simulations in this study were carried out on the Cy-Tera cluster. The project Cy-Tera (NEAYПО $\Delta$ OMH/ $\Sigma$ TPATH/0308/31) is co-financed by the European Regional Development Fund and the Republic of Cyprus through the Research Promotion Foundation. The research leading to these results has received funding from the European Research Council under the European Union's Seventh Framework Programme (FP7/2007-2013)/ERC grant agreement no. 226144. The authors thank the NASA AERONET team for providing the AERONET data used in this study and the team of Mr. Savvas Kleathous, Cyprus Ministry of Labour and Social Insurance, for providing the sulfate, calcium and PM observations at Ayia Marina station (Cyprus). The authors thank the Remote sensing and Geo-Environment Research laboratory of Cyprus University of Technology (CUT) for providing the lidar extinction profiles at the CUT-TEPAK station.

Edited by: M. Kanakidou 


\section{References}

Alpert, P. and Ganor, E.: A jet stream associated heavy dust storm in the western Mediterranean, J. Geophys. Res., 98, 7339, doi:10.1029/92JD01642, 1993.

Ardon-Dryer, K. and Levin, Z.: Ground-based measurements of immersion freezing in the eastern Mediterranean, Atmos. Chem. Phys., 14, 5217-5231, doi:10.5194/acp-14-5217-2014, 2014.

Astitha, M., Kallos, G., Spyrou, C., O'Hirok, W., Lelieveld, J., and Denier van der Gon, H. A. C.: Modelling the chemically aged and mixed aerosols over the eastern central Atlantic Ocean - potential impacts, Atmos. Chem. Phys., 10, 5797-5822, doi:10.5194/acp-10-5797-2010, 2010.

Astitha, M., Lelieveld, J., Abdel Kader, M., Pozzer, A., and de Meij, A.: Parameterization of dust emissions in the global atmospheric chemistry-climate model EMAC: impact of nudging and soil properties, Atmos. Chem. Phys., 12, 11057-11083, doi:10.5194/acp-12-11057-2012, 2012.

Bauer, S. E., Balkanski, Y., Schulz, M., Hauglustaine, D. A., and Dentener, F.: Global modeling of heterogeneous chemistry on mineral aerosol surfaces: influence on tropospheric ozone chemistry and comparison to observations, J. Geophys. Res.-Atmos., 109, D02304, doi:10.1029/2003JD003868, 2004.

Bauer, S. E., Mishchenko, M. I., Lacis, A. A., Zhang, S., Perlwitz, J., and Metzger, S. M.: Do sulfate and nitrate coatings on mineral dust have important effects on radiative properties and climate modeling?, J. Geophys. Res., 112, D0630, doi:10.1029/2005JD006977, 2007.

Crowley, J. N., Ammann, M., Cox, R. A., Hynes, R. G., Jenkin, M. E., Mellouki, A., Rossi, M. J., Troe, J., and Wallington, T. J.: Evaluated kinetic and photochemical data for atmospheric chemistry: Volume V - heterogeneous reactions on solid substrates, Atmos. Chem. Phys., 10, 9059-9223, doi:10.5194/acp-10-90592010, 2010.

Dayan, U., Heffter, J., Miller, J., and Gutman, G.: Dust intrusion events into the Mediterranean Basin, J. Appl. Meteorol., 30, 1185-1199, doi:10.1175/15200450(1991)030<1185:DIEITM>2.0.CO;2, 1991.

Dayan, U., Ziv, B., Shoob, T., and Enzel, Y.: Suspended dust over southeastern Mediterranean and its relation to atmospheric circulations, Int. J. Climatol., 28, 915-924, doi:10.1002/joc.1587, 2008.

de Meij, A. and Lelieveld, J.: Evaluating aerosol optical properties observed by ground-based and satellite remote sensing over the Mediterranean and the Middle East in 2006, Atmos. Res., 99, 415-433, doi:10.1016/j.atmosres.2010.11.005, 2011.

de Meij, A., Pozzer, A., Pringle, K., Tost, H., and Lelieveld, J.: EMAC model evaluation and analysis of atmospheric aerosol properties and distribution with a focus on the Mediterranean region, Atmos. Res., 114-115, 38-69, doi:10.1016/j.atmosres.2012.05.014, 2012.

Dentener, F. J., Carmichael, G. R., Zhang, Y., Lelieveld, J., and Crutzen, P. J.: Role of mineral aerosol as a reactive surface in the global troposphere, J. Geophys. Res., 101, 22869, doi:10.1029/96JD01818, 1996.

Fountoukis, C. and Nenes, A.: ISORROPIA II: a computationally efficient thermodynamic equilibrium model for $\mathrm{K}^{+}-\mathrm{Ca}^{2+}$ $\mathrm{Mg}^{2+}-\mathrm{NH}^{4+}-\mathrm{Na}^{+}-\mathrm{SO}_{4}^{2-}-\mathrm{NO}_{3}^{-}-\mathrm{Cl}^{-}-\mathrm{H}_{2} \mathrm{O}$ aerosols, Atmos.
Chem. Phys., 7, 4639-4659, doi:10.5194/acp-7-4639-2007, 2007.

Fuchs, N. A. and Davies, C. N.: The mechanics of aerosols, Dover Publications, New York, 1989.

Ganor, E. and Mamane, Y.: Transport of Saharan dust across the eastern Mediterranean, Atmos. Environ., 16, 581-587, doi:10.1016/0004-6981(82)90167-6, 1982.

Ganor, E., Osetinsky, I., Stupp, A., and Alpert, P.: Increasing trend of African dust, over 49 years, in the eastern Mediterranean, J. Geophys. Res., 115, D07201, doi:10.1029/2009JD012500, 2010.

Gläser, G., Kerkweg, A., and Wernli, H.: The Mineral Dust Cycle in EMAC 2.40: sensitivity to the spectral resolution and the dust emission scheme, Atmos. Chem. Phys., 12, 1611-1627, doi:10.5194/acp-12-1611-2012, 2012.

Goudie, A. and Middleton, N.: Desert Dust in the Global System, Springer, Berlin, New York, 292, 2006.

Holben, B., Eck, T., Slutsker, I., Tanré, D., Buis, J., Setzer, A., Vermote, E., Reagan, J., Kaufman, Y., Nakajima, T., Lavenu, F., Jankowiak, I., and Smirnov, A.: AERONET - a federated instrument network and data archive for Aerosol characterization, Remote Sens. Environ., 66, 1-16, doi:10.1016/S00344257(98)00031-5, 1998.

Jöckel, P., Kerkweg, A., Pozzer, A., Sander, R., Tost, H., Riede, H., Baumgaertner, A., Gromov, S., and Kern, B.: Development cycle 2 of the Modular Earth Submodel System (MESSy2), Geosci. Model Dev., 3, 717-752, doi:10.5194/gmd-3-717-2010, 2010.

Johnson, M. S., Meskhidze, N., and Praju Kiliyanpilakkil, V.: A global comparison of GEOS-Chem-predicted and remotely-sensed mineral dust aerosol optical depth and extinction profiles, J. Adv. Model. Earth Syst, 4, M07001, doi:10.1029/2011MS000109, 2012.

Kallos, G., Papadopoulos, A., Katsafados, P., and Nickovic, S.: Transatlantic Saharan dust transport: model simulation and results, J. Geophys. Res., 111, D09204, doi:10.1029/2005JD006207, 2006.

Kanitz, T., Ansmann, A., Foth, A., Seifert, P., Wandinger, U., Engelmann, R., Baars, H., Althausen, D., Casiccia, C., and Zamorano, F.: Surface matters: limitations of CALIPSO V3 aerosol typing in coastal regions, Atmos. Meas. Tech., 7, 2061-2072, doi:10.5194/amt-7-2061-2014, 2014.

Koop, T. and Mahowald, N.: Atmospheric science: the seeds of ice in clouds, Nature, 498, 302-303, doi:10.1038/nature12256, 2013.

Lelieveld, J., Berresheim, H., Borrmann, S., Crutzen, P. J., Dentener, F. J., Fischer, H., Feichter, J., Flatau, P. J., Heland, J., Holzinger, R., Korrmann, R., Lawrence, M. G., Levin, Z., Markowicz, K. M., Mihalopoulos, N., Minikin, A., Ramanathan, V., de Reus, M., Roelofs, G. J., Scheeren, H. A., Sciare, J., Schlager, H., Schultz, M., Siegmund, P., Steil, B., Stephanou, E. G., Stier, P., Traub, M., Warneke, C., Williams, J., and Ziereis, H.: Global air pollution crossroads over the Mediterranean, Science, 298, 794-799, doi:10.1126/science.1075457, 2002.

Levin, Z., Ganor, E., and Gladstein, V.: The effects of desert particles coated with sulfate on rain formation in the Eastern Mediterranean, J. Appl. Meteorol., 35, 1511-1523, doi:10.1175/15200450(1996)035<1511:TEODPC>2.0.CO;2, 1996.

Levin, Z., Teller, A., Ganor, E., and Yin, Y.: On the interactions of mineral dust, sea-salt particles, and clouds: a measurement and modeling study from the Mediterranean Israeli Dust Ex- 
periment campaign, J. Geophys. Res.-Atmos., 110, D20202, doi:10.1029/2005JD005810, 2005.

Liu, Z., Omar, A., Vaughan, M., Hair, J., Kittaka, C., Hu, Y., Powell, K., Trepte, C., Winker, D., Hostetler, C., Ferrare, R., and Pierce, R.: CALIPSO lidar observations of the optical properties of Saharan dust: a case study of long-range transport, J. Geophys. Res., 113, D07207, doi:10.1029/2007JD008878, 2008.

Mahowald, N. M., Engelstaedter, S., Luo, C., Sealy, A., Artaxo, P., Benitez-Nelson, C., Bonnet, S., Chen, Y., Chuang, P. Y., Cohen, D. D., Dulac, F., Herut, B., Johansen, A. M., Kubilay, N., Losno, R., Maenhaut, W., Paytan, A., Prospero, J. M., Shank, L. M., and Siefert, R. L.: Atmospheric iron deposition: global distribution, variability, and human perturbations, Annu. Rev. Marine Sci., 1, 245-278, doi:10.1146/annurev.marine.010908.163727, 2009.

Mamouri, R. E. and Ansmann, A.: Fine and coarse dust separation with polarization lidar, Atmos. Meas. Tech., 7, 3717-3735, doi:10.5194/amt-7-3717-2014, 2014.

Mamouri, R. E. and Ansmann, A.: Estimated desert-dust ice nuclei profiles from polarization lidar: methodology and case studies, Atmos. Chem. Phys., 15, 3463-3477, doi:10.5194/acp-15-34632015, 2015.

Mamouri, R. E., Ansmann, A., Nisantzi, A., Kokkalis, P., Schwarz, A., and Hadjimitsis, D.: Low Arabian dust extinction-tobackscatter ratio: Arabian dust lidar ratio, Geophys. Res. Lett., 4762-4766, doi:10.1002/grl.50898, 2013.

Manktelow, P. T., Carslaw, K. S., Mann, G. W., and Spracklen, D. V.: The impact of dust on sulfate aerosol, $\mathrm{CN}$ and $\mathrm{CCN}$ during an East Asian dust storm, Atmos. Chem. Phys., 10, 365-382, doi:10.5194/acp-10-365-2010, 2010.

Metzger, S., Mihalopoulos, N., and Lelieveld, J.: Importance of mineral cations and organics in gas-aerosol partitioning of reactive nitrogen compounds: case study based on MINOS results, Atmos. Chem. Phys., 6, 2549-2567, doi:10.5194/acp-6-25492006, 2006.

Mogili, P. K., Kleiber, P. D., Young, M. A., and Grassian, V. H.: Heterogeneous uptake of ozone on reactive components of mineral dust aerosol: an environmental aerosol reaction chamber study, J. Phys. Chem. A, 110, 13799-13807, doi:10.1021/jp063620g, 2006.

Moulin, C., Lambert, C. E., Dayan, U., Masson, V., Ramonet, M., Bousquet, P., Legrand, M., Balkanski, Y. J., Guelle, W., Marticorena, B., Bergametti, G., and Dulac, F.: Satellite climatology of African dust transport in the Mediterranean atmosphere, J. Geophys. Res., 103, 13137, doi:10.1029/98JD00171, 1998.

Nenes, A., Krom, M. D., Mihalopoulos, N., Van Cappellen, P., Shi, Z., Bougiatioti, A., Zarmpas, P., and Herut, B.: Atmospheric acidification of mineral aerosols: a source of bioavailable phosphorus for the oceans, Atmos. Chem. Phys., 11, 6265-6272, doi:10.5194/acp-11-6265-2011, 2011.

Nisantzi, A., Mamouri, R. E., Ansmann, A., and Hadjimitsis, D.: Injection of mineral dust into the free troposphere during fire events observed with polarization lidar at Limassol, Cyprus, Atmos. Chem. Phys., 14, 12155-12165, doi:10.5194/acp-1412155-2014, 2014.

Papayannis, A., Balis, D., Amiridis, V., Chourdakis, G., Tsaknakis, G., Zerefos, C., Castanho, A. D. A., Nickovic, S., Kazadzis, S., and Grabowski, J.: Measurements of Saharan dust aerosols over the Eastern Mediterranean using elastic backscatter-Raman lidar, spectrophotometric and satellite observations in the frame of the EARLINET project, Atmos. Chem. Phys., 5, 2065-2079, doi:10.5194/acp-5-2065-2005, 2005.

Pey, J., Querol, X., Alastuey, A., Forastiere, F., and Stafoggia, M.: African dust outbreaks over the Mediterranean Basin during 2001-2011: $\mathrm{PM}_{10}$ concentrations, phenomenology and trends, and its relation with synoptic and mesoscale meteorology, Atmos. Chem. Phys., 13, 1395-1410, doi:10.5194/acp-13-13952013, 2013.

Pozzer, A., de Meij, A., Pringle, K. J., Tost, H., Doering, U. M., van Aardenne, J., and Lelieveld, J.: Distributions and regional budgets of aerosols and their precursors simulated with the EMAC chemistry-climate model, Atmos. Chem. Phys., 12, 961-987, doi:10.5194/acp-12-961-2012, 2012.

Pringle, K. J., Tost, H., Metzger, S., Steil, B., Giannadaki, D., Nenes, A., Fountoukis, C., Stier, P., Vignati, E., and Lelieveld, J.: Corrigendum to "Description and evaluation of GMXe: a new aerosol submodel for global simulations (v1)" published in Geosci. Model Dev., 3, 391-412, 2010, Geosci. Model Dev., 3, 413-413, doi:10.5194/gmd-3-413-2010, 2010.

Reitz, P., Spindler, C., Mentel, T. F., Poulain, L., Wex, H., Mildenberger, K., Niedermeier, D., Hartmann, S., Clauss, T., Stratmann, F., Sullivan, R. C., DeMott, P. J., Petters, M. D., Sierau, B., and Schneider, J.: Surface modification of mineral dust particles by sulphuric acid processing: implications for ice nucleation abilities, Atmos. Chem. Phys., 11, 7839-7858, doi:10.5194/acp-117839-2011, 2011.

Roeckner, E., Brokopf, R., Esch, M., Giorgetta, M., Hagemann, S., Kornblueh, L., Manzini, E., Schlese, U., and Schulzweida, U.: Sensitivity of simulated climate to horizontal and vertical resolution in the ECHAM5 atmosphere model, J. Climate, 19, 37713791, doi:10.1175/JCLI3824.1, 2006.

Rosenfeld, D., Rudich, Y., and Lahav, R.: Desert dust suppressing precipitation: a possible desertification feedback loop, P. Natl Acad. Sci. USA, 98, 5975-5980, doi:10.1073/pnas.101122798, 2001.

Sander, R., Kerkweg, A., Jöckel, P., and Lelieveld, J.: Technical note: The new comprehensive atmospheric chemistry module MECCA, Atmos. Chem. Phys., 5, 445-450, doi:10.5194/acp-5445-2005, 2005.

Schulz, M., Prospero, J. M., Baker, A. R., Dentener, F., Ickes, L., Liss, P. S., Mahowald, N. M., Nickovic, S., García-Pando, C. P., Rodríguez, S., Sarin, M., Tegen, I., and Duce, R. A.: Atmospheric transport and deposition of mineral dust to the ocean: implications for research needs, Environ. Sci. Technol., 46, 10390 10404, doi:10.1021/es300073u, 2012.

Schuster, G. L., Vaughan, M., MacDonnell, D., Su, W., Winker, D., Dubovik, O., Lapyonok, T., and Trepte, C.: Comparison of CALIPSO aerosol optical depth retrievals to AERONET measurements, and a climatology for the lidar ratio of dust, Atmos. Chem. Phys., 12, 7431-7452, doi:10.5194/acp-12-7431-2012, 2012.

Seinfeld, J. H. and Pandis, S. N.: Atmospheric chemistry and physics: from air pollution to climate change, J. Wiley, Hoboken, N.J., 2006.

Stocker, T. F., Qin, D., Plattner, G. K., Tignor, M., Allen, S. K., Boschung, J., Nauels, A., Xia, Y., Bix, V., and Midgley, P. M.: Climate Change 2013: the Physical Science Basis: Working Group I Contribution to the Fifth Assessment Report of the Inter- 
governmental Panel on Climate Change, Cambridge University Press, New York, 2014.

Su, L. and Toon, O. B.: Saharan and Asian dust: similarities and differences determined by CALIPSO, AERONET, and a coupled climate-aerosol microphysical model, Atmos. Chem. Phys., 11, 3263-3280, doi:10.5194/acp-11-3263-2011, 2011.

Taylor, K. E.: Summarizing multiple aspects of model performance in a single diagram, J. Geophys. Res., 106, 7183, doi:10.1029/2000JD900719, 2001.

Teller, A., Xue, L., and Levin, Z.: The effects of mineral dust particles, aerosol regeneration and ice nucleation parameterizations on clouds and precipitation, Atmos. Chem. Phys., 12, 93039320, doi:10.5194/acp-12-9303-2012, 2012.

Tost, H., Jöckel, P., Kerkweg, A., Sander, R., and Lelieveld, J.: Technical note: A new comprehensive SCAVenging submodel for global atmospheric chemistry modelling, Atmos. Chem. Phys., 6, 565-574, doi:10.5194/acp-6-565-2006, 2006.

Tost, H., Lawrence, M. G., Brühl, C., Jöckel, P., The GABRIEL Team, and The SCOUT-O3-DARWIN/ACTIVE Team: Uncertainties in atmospheric chemistry modelling due to convection parameterisations and subsequent scavenging, Atmos. Chem. Phys., 10, 1931-1951, doi:10.5194/acp-10-1931-2010, 2010.
Trebs, I., Metzger, S., Meixner, F. X., Helas, G., Hoffer, A., Rudich, Y., Falkovich, A. H., Moura, M. A. L., da Silva, R. S., Artaxo, P., Slanina, J., and Andreae, M. O.: The $\mathrm{NH}_{4}^{+}-\mathrm{NO}_{3}^{-}-\mathrm{Cl}^{-}-\mathrm{SO}_{4}^{2-}-$ $\mathrm{H}_{2} \mathrm{O}$ aerosol system and its gas phase precursors at a pasture site in the Amazon Basin: how relevant are mineral cations and soluble organic acids?, J. Geophys. Res.-Atmos., 110, D07303, doi:10.1029/2004JD005478, 2005.

Uno, I., Eguchi, K., Yumimoto, K., Liu, Z., Hara, Y., Sugimoto, N., Shimizu, A., and Takemura, T.: Large Asian dust layers continuously reached North America in April 2010, Atmos. Chem. Phys., 11, 7333-7341, doi:10.5194/acp-11-7333-2011, 2011.

van der Werf, G. R., Randerson, J. T., Giglio, L., Collatz, G. J., Mu, M., Kasibhatla, P. S., Morton, D. C., DeFries, R. S., Jin, Y., and van Leeuwen, T. T.: Global fire emissions and the contribution of deforestation, savanna, forest, agricultural, and peat fires (19972009), Atmos. Chem. Phys., 10, 11707-11735, doi:10.5194/acp10-11707-2010, 2010.

Yin, Y., Wurzler, S., Levin, Z., and Reisin, T. G.: Interactions of mineral dust particles and clouds: effects on precipitation and cloud optical properties, J. Geophys. Res.-Atmos., 107, 4724, doi:10.1029/2001JD001544, 2002. 